\title{
Two-Stage Expression of Neurofilament Polypeptides During Rat Neurogenesis with Early Establishment of Adult Phosphorylation Patterns
}

\author{
Martin J. Carden, John Q. Trojanowski, William W. Schlaepfer, and Virginia M.-Y. Lee \\ The Division of Neuropathology, Department of Pathology and Laboratory Medicine, University of Pennsylvania School of \\ Medicine, Philadelphia, Pennsylvania 19104
}

Monoclonal antibodies (mAbs) to rat neurofilament (NF) proteins NF-L, NF-M, and NF-H were used to examine the developmental programs of NF expression in rat embryos. The ability of these mAbs to recognize differentially phosphorylated states of NF-M and NF-H (Lee et al., 1987, the preceding paper) was exploited in order to examine the temporal and spatial patterns of NF phosphorylation during early neuronal development in vivo. NF proteins were first detected on the twelfth day postfertilization (E12) using NF-Lor NF-M-specific mAbs. By E13, the coexpression of NF-L and NF-M was widespread, reflecting dramatic increases of immunoreactivity to both subunits. Partial phosphorylation, denoted $\mathrm{P}[+]$, of NF-M was already present in perikarya and neurites of E12 neurons. Extensively phosphorylated, or $P[+++]$, isoforms of NF-M appeared in E13 axons, thereby establishing a proximodistal gradient of NF phosphorylation during the earliest phase of NF expression. Immunoblots of tissue homogenates revealed that most NF-M of E13 embryos exists in a partially phosphorylated, or $\mathrm{P}[+]$, isoform.

Unequivocal staining for NF-H first appeared at E15, a time at which NF-L and NF-M had already attained their adult patterns of immunocytochemical staining. Levels of NF-H were extremely low at $\mathrm{E} 15$ but could be detected in all of its differentially phosphorylated states, i.e., nonphosphorylated $\mathbf{P}[-]$, partly $\mathbf{P}[+]$, and highly $\mathbf{P}[+++]$ phosphorylated isoforms. $P[+++]$ isoforms of NF-H were restricted to the distal portions of E15 axons, although staining of more proximal axons, like those in adult, was noted by E17. Immunoblots of E17 embryos revealed most NF-H as $P[-]$ and $P[+]$ isoforms. Quantities of immunoreactive NF-H increased very slowly and remained well below those of NF-M and NF-L for several weeks beyond birth.

These results show that sequential forms of NFs are expressed by developing and maturing neurons throughout the

\footnotetext{
Received Jan. 20, 1987; revised May 8, 1987; accepted May 14, 1987.

This work was supported by a Postdoctoral Fellowship (M.J.C.) from the National ALS Foundation of America and by NIH Grants CA-36245 (J.Q.T.), NS15722 (W.W.S.), NS-18616 (V.M.Y.L.), and PO-AG-06107. Grateful thanks are expressed to Ms. C. Page for maintaining hybridomas and supplies of antibody, to Ms. J. Bruce and Ms. T. Schuck for paraffin-embedding and sectioning of specimens, to Mr. M. Memmo for help with the figures, and to Drs. M. Goldstein and M. L. Schmidt for sharing their experiences with immunostaining features of the same antibodies from other studies of adult rat and human tissues.

Correspondence should be addressed to Martin J. Carden, 435 Johnson Pavilion, Division of Neuropathology, Department of Pathology and Laboratory Medicine, University of Pennsylvania School of Medicine, 36th Street and Hamilton Walk, Philadelphia, PA 19104-6079.

Copyright (C) 1987 Society for Neuroscience $0270-6474 / 87 / 113489-16 \$ 02.00 / 0$
}

nervous system. An "immature" form of NFs, composed of NF-M and NF-L, appears to function in establishing the neuronal phenotype and in initiating and maintaining neurite outgrowth. Addition of NF-H confers a "mature" state to the NF. This delayed expression of NF-H is a slow and graduated process that coincides in time with the stabilization of neuronal circuitries and may be important in modulating axonal events, such as the slowing of cytoskeletal transport and the growth of axonal caliber.

Neurofilaments (NFs) are neuron-specific cytoskeletal components that allow nerve cells to establish and maintain a remarkably complex set of highly asymmetrical cellular extensions. Antibodies have proved important in identifying 3 polypeptides (NF-L, NF-M, and NF-H) as the major components of mammalian NFs (Schlacpfer and Lynch, 1977; Licm et al., 1978; Anderton et al., 1980; Willard et al., 1980; Shaw et al., 1981; Yen and Fields, 1981; Autilio-Gambetti et al., 1986), and they have also been a major tool for examining the expression of NF subunits during development. Several authors have obtained evidence that NF-H appears later in neurons than do NF-L and NF-M (Shaw and Weber, 1982, 1983; Willard and Simon, 1983; Pachter and Liem, 1984; Harry et al., 1985; Nona et al., 1985), and some suggest that NF-M may be synthesized first (Pachter and Liem, 1984; Bennett and DiLullo, 1985a). In the only study to examine the earliest appearance of NFs in the mammalian neuroepithelium using antibodies specific for each component (Cochard and Paulin, 1984), it was concluded that all 3 NF polypeptides appear simultaneously. While these different results might reflect species variations and/ or asynchronous programming of neuronal differentiation (e.g. Altman and Bayer, 1982, 1984, 1986), a more compelling explanation may relate to the extensive phosphorylation of NF$\mathrm{H}$, which profoundly affects its migration in gels (Julien and Mushynski, 1982) and its antigenicity (Sternberger and Sternberger, 1983). Indeed, the great majority of antisera and monoclonal antibodies (mAbs) raised to conventional preparations of NF-H recognize only its phosphorylated forms (e.g., Carden et al., 1985; Glicksman and Willard, 1985; Lee et al., 1986a, b; Shaw et al., 1986). Hence, the delayed detection of NF-H during development by immunological or electrophoretic methods may reflect a delay in the posttranslational modification, rather than in the expression of NF-H (Dahl et al., 1986).

The previous paper (Lee et al., 1987) describes a comprehensive library of mAbs that recognizes each rat NF protein specifically and can detect the 2 larger subunits, NF-M and NF-H, 


\begin{tabular}{|c|c|}
\hline Specificity & Antibody name(s) \\
\hline \multicolumn{2}{|c|}{$\mathrm{NF}$-H-specific $\mathrm{m} \Lambda \mathrm{bs}$} \\
\hline $\mathbf{P}[+++]$ & $\mathrm{RMO} 24$ \\
\hline $\mathrm{P}[++1$ & RMO217 \\
\hline $\mathrm{P}[+]$ & Ta5 1 \\
\hline$P[-]$ & $\begin{array}{l}\text { dP1, RMO81, }{ }^{a} \text { RMO205, }{ }^{a} \text { RMO304, } \\
\text { RMdT2, RMdO9, RMdO18, } \\
\text { RMdO20 }\end{array}$ \\
\hline $\mathrm{P}[$ ind-core $]$ & $\operatorname{Ta} 56^{b}$ \\
\hline \multicolumn{2}{|c|}{ NF-M-specific mAbs } \\
\hline $\mathrm{P}[+++]$ & RMO45, RMO55 \\
\hline $\mathrm{P}[++]$ & RMO55 \\
\hline $\mathrm{P}[+]$ & RMO93, RMO108, RMdO4 \\
\hline $\mathbf{P}[$ ind-periph $]$ & $\mathrm{RMO}^{a}$ \\
\hline $\mathbf{P}[$ ind-core $]$ & $\mathrm{RMO} 43,{ }^{b} \mathrm{RMdO} 10,{ }^{a} \mathrm{Ta}^{2} 4^{b}$ \\
\hline \multicolumn{2}{|c|}{ NF-L-specific mAbs } \\
\hline All P[ind] & $\operatorname{RMS} 12,{ }^{a} \operatorname{RMS} 21^{b}$ \\
\hline
\end{tabular}

Monoclonal antibodies (mAbs) were selected from previously well-characterized libraries (Carden ct al., 1985; Lee et al., 1986b, 1987) on the basis of their ability to recognize a single rat NF subunit by immunoblotting, and to stain tissues specifically.

"Antibodies stained chemically fixed tissues and immunoblots only weakly.

"Antibodies did not stain chemically fixed tissue, but could be used for immunofluorescence studies on frozen sections.

in several of their immunologically distinct, differentially phosphorylated states. This library was used here to reinvestigate both the timing of NF subunit expression and the timing and spatial patterns of NF-H and NF-M phosphorylation during rat neurogenesis in vivo. The latter issue has received only limited, and recent, attention (Dahl and Bignami, 1986; Dahl et al., 1986; Noetzel et al., 1986).

\section{Materials and Methods}

Animals. Pregnant Sprague-Dawley rats were obtained from Charles River Laboratories (Wilmington, MA) on day 8 following an overnight mating (denoted E8). To verify staging assignments, morphological and histological features of these rat embryos were routinely compared and found to be consistent with those from previous reference studies (e.g., Adelmann, 1925; Windle and Baxter, 1936a, b; Nornes and Das, 1974; Beaudoin, 1980; Altman and Bayer, 1982, 1984, 1986). In all, rats from over 50 litters (10-15 embryos each) were examined; these were taken from dams that arrived in 15 separate consignments of 2-8 animals each (median 4 ). These litters were nearly equally divided between 14 different sequential embryonic (E) and postnatal day (PND) timepoints from E9 through PND21 (E9-E19, E21, E22/PND0, PND21), with a slight bias around E11-E15.

Antibodies. The mAbs selected for this study were generated and screened against phosphorylated and dephosphorylated adult rat NF antigens (Lee et al., 1987). Their properties are summarized in $\mathrm{Ta}$ ble 1 .

\section{Tissue preparation for immunohistochemistry}

Tissue sampling. E9-E11 embryos were processed without dissecting them free of the uterine wall. E12-E14 embryos were dissected free of the uterus and extraembryonic membranes before being processed in toto. E15-E1 7 embryos were divided into head, thorax, and lower segments for separate processing. The whole spinal column was dissected free of visceral organs and of other, more distal, tissues in older embryos (E18-E20). Segments of spinal cord and individual dorsal root ganglia (DRGs) were obtained from early postnatal animals (PND0-PND21) Adult rat (150 gm body weight or larger) tissues were studied as described in the previous paper (Lee et al., 1987).

Wax embedding. Tissue was fixed for $6 \mathrm{hr}$ at $21^{\circ} \mathrm{C}$ by immersion in
Bouin's fixative (2\% acetic acid, $10 \%$ formalin dissolved in saturated picric acid and normal saline). Tissue was then washed in several changes of Tris-buffered saline (TBS: $50 \mathrm{~mm}$ Tris, $150 \mathrm{~mm} \mathrm{NaCl}$ adjusted to $\mathrm{pH}$ 7.3 with $\mathrm{HCl}$ ) at $21^{\circ} \mathrm{C}$ for over $24 \mathrm{hr}$. Tissue was dehydrated through graded ethanol solutions and xylene to Paraplast wax at $60^{\circ} \mathrm{C}$ on an Autotechnikon. Wax-embdded 6- $\mu \mathrm{m}$-thick tissue sections were collected onto poly-L-lysine (high $M_{\mathrm{r}}$ )-coated slides and dried overnight at $42^{\circ} \mathrm{C}$.

Frozen sections. Tissue was rapidly frozen onto a chuck at $-20^{\circ} \mathrm{C}$ after being embedded in Tissue-Tek OCT (Miles Scientific, Naperville, IL). Sections were cut at a thickness of $20 \mu \mathrm{m}$, collected onto poly-Llysine-coated slides, and dried (heat-fixed) overnight in an oven at $42^{\circ} \mathrm{C}$.

\section{Immunohistochemical methods}

Avidin-biotin complex $(A B C)$ method. Wax sections were deparaffinized by immersion for $>1 \mathrm{hr}$ each in xylene, Histoclear (National Diagnostics, Somerville, NJ), and fresh xylene. They were then taken to $70 \%$ ethanol and quenched with $70 \%$ ethanol $/ 5 \% \mathrm{H}_{2} \mathrm{O}_{2}$ for $30 \mathrm{~min}$. Rehydration was continued to water and the slides were rinsed twice $(10 \mathrm{~min}$ each) in TBS. Prior to application of primary antibody, sections were immersed for $>5 \mathrm{~min}$ in a blocking solution ( $1 \% \mathrm{BSA}, 2 \% \mathrm{fctal}$ bovinc serum, and $1 \% \lambda$-globulin-free horse serum dissolved in TBS), which was also used to dilute mAbs when necessary. Subsequent steps in the immunoperoxidase procedures used here, including enhancement of the diaminobenzidine reaction with imidazole (Trojanowski et al., 1983), have been detailed in several recent reports from our laboratories (Lee et al., 1986b; Goldstein et al., 1987; Schmidt et al., 1987).

Immunofluorescence. Air-dried frozen sections were rehydrated by immersion in blocking solution and then incubated with primary antibodies, as described above. Slides were washed $(>1 \mathrm{hr})$ using several changes of TBS, and rhodamine-conjugated antibody diluted 50 -fold in blocking solution was applied for $2 \mathrm{hr}$. Slides were again rinsed for an hour and then coverslipped in Aquamount.

\section{Immunoblotting embryonic tissue}

E13 embryos were dissected from the uterus, rinsed twice with TBS, and homogenized in glass/glass tight-fitting tissue grinders using BUST ( $1 \% \beta$-mercaptoethanol, $8.0 \mathrm{~m}$ urea, $1 \% \mathrm{SDS}, 60 \mathrm{~mm}$ Tris- $\mathrm{HCl}$, $\mathrm{pH} 6.8$ ). At E17, the spinal cord was removed and processed similarly. About $50 \mu \mathrm{l}$ of BUST was used per E13 embryo, and $100 \mu \mathrm{l}$ per whole E17 spinal cord. DNAase I (about $5 \mathrm{mg}$ ) and $\mathrm{MgCl}_{2}$ (to $1 \mathrm{~mm}$ ) were added during later stages of homogenization, and samples were centrifuged for $2 \mathrm{hr}$ at top speed in a Beckman Airfuge $30^{\circ}$ angle rotor. The supernatants were used for gels (see below). Other standard proteins such as molecular weight markers (Bio-Rad) and enzymatically dephosphorylated, or untreated, rat NFs (Lee et al., 1987) were also dissolved in BUST. Polyacrylamide $(7.5 \%)$ gels were used to resolve proteins (Carden et al., 1985 ) and bands were transferred to nitrocellulose paper (Schleicher and Schuell; $0.45 \mu \mathrm{m}$ ) using $182 \mathrm{~mm}$ glycine, $25 \mathrm{~mm}$ Tris (pH 8.3) as transfer buffer and a Hoefer Transphor apparatus operated at $1000 \mathrm{~mA}$ for $30 \mathrm{~min}$ at $10^{\circ} \mathrm{C}$. Electroblots were placed in TBS containing $1 \% \mathrm{BSA}$ and 5\% dried milk (Carnation) for $1 \mathrm{hr}$ to block unused protein-binding capacity of the nitrocellulose paper. Antibodies were applied overnight and their binding was visualized using peroxidase-conjugated antibodies and 4-chloronaphthol (Carden et al., 1985) or by the peroxidase-antiperoxidase (PAP) complex methodology, using diaminobenzidine as chromogen (Lee et al., 1987).

\section{Results}

Earliest expression of $N F$ proteins: $N F-L$ and $N F-M$ without $N F-H$ in $E 12$ rat neurons

NF-specific immunoreactivity was first observed convincingly at E12 using mAbs to NF-L (see Fig. 1 $a$ ) and certain types of NF-M-specific mAbs (Figs. $1, b-d ; 2, d-i$ ). Both subunits were present in the same sets of cells at the outer margin of the E12 neuroepithelium (compare Fig. 1, $a$ and $b$ ). In some cases, NFL-specific immunofluorescence (Fig. 1a) appeared somewhat stronger than that for NF-M in nearly adjacent sections (Fig. 1, $b-d)$, possibly reflecting differences in antibody affinities or antigenic preservation. Indeed, NF-L-specific mAbs did not stain 

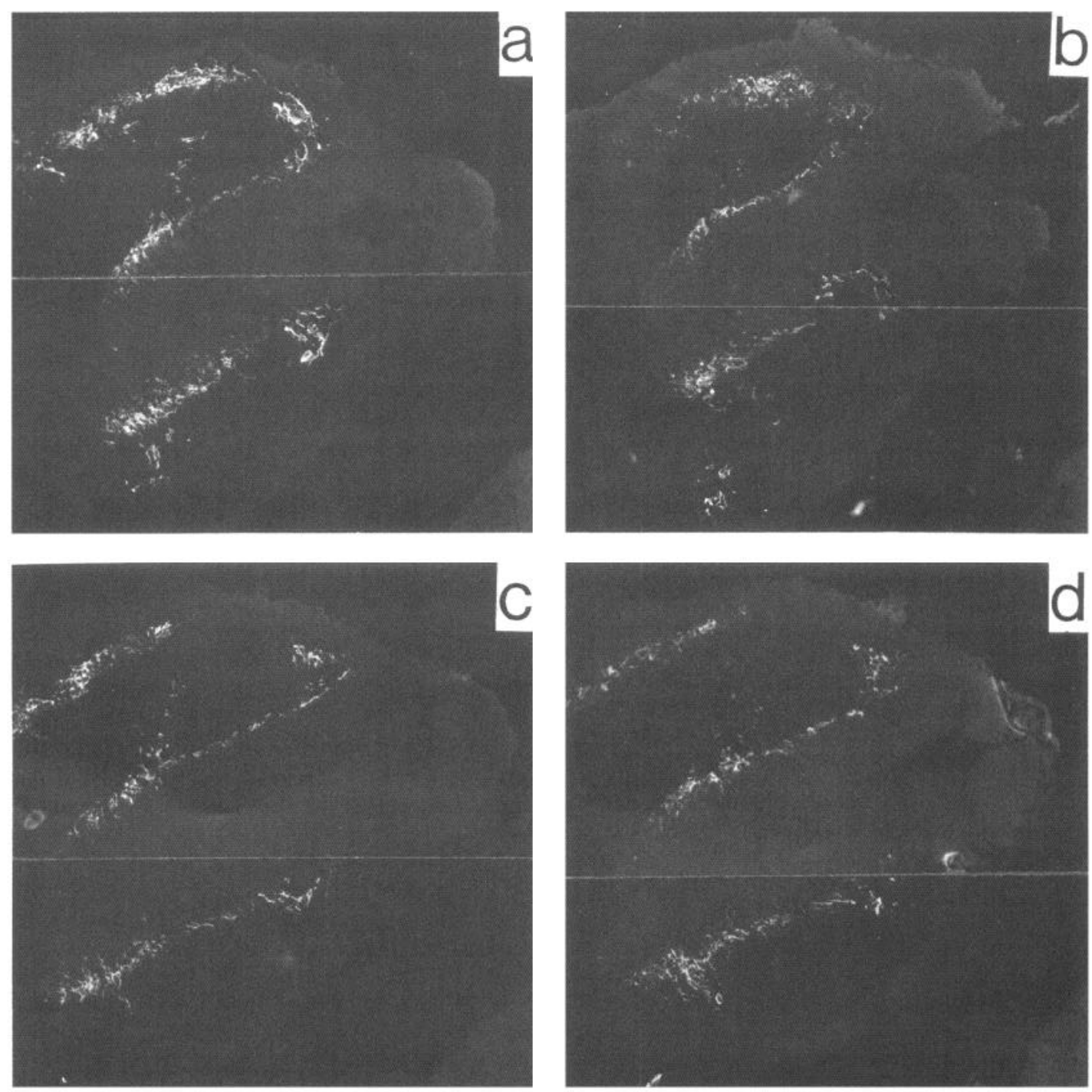

Figure 1. Neurofilament immunoreactivity in 20- $\mu$ m-thick frozen sections of E12 rat embryos detected by immunofluorescence using a mAb specific for NF-L $(a)$ and 3 different kinds of mAb specific for NF-M $(b-d)$. The sections were taken from the same embryo (in a series of 50 consecutive sections cut at $20 \mu \mathrm{m}$ ). Properties and identities of the mAbs (Lee et al., 1987) were as follows: $a$, RMS21, P[ind]: NF-L-specific; $b$, RMO43, P[ind-core]: NF-M-specific; $c$, RMO3, P[ind-periph]: NF-M-specific; $d$, RMO93, P[+]: NF-M-specific. The width of each photograph represents approximately $1120 \mu \mathrm{m}$.

Bouin's-fixed wax sections well, even in adults (Lee et al., 1987), although the enhanced preservation of morphology in such tissue (Fig. 2), as compared to frozen sections (Fig. 1), allowed the detailed anatomical identification of cells expressing NF-M at E12. In nearly midsagittal sections, numerous neurons at the outer edge of the rhombencephalon were NF-M-positive throughout, including both perikarya and short neurites (Fig. 2, $g, h$ ). In more parasagittal sections (Fig. 2, $a, d, e$ ) NF-M was present in clusters of cells rostral to the otic vesicles, neurons destined to form various brain stem ganglia (VII-VIII and the trigeminal, or V; for anatomy see Adelmann, 1925; Altman and Bayer, 1982). Neurons and processes at the outside edge of the spinal cord/brain stem contained progressively less NF-M-specific immunoreactivity proceeding in the caudal direction along the neuroaxis (Fig. 2, $a, b, f, i$ ). This pattern follows closely the rostrocaudal progression of neurogenesis along the developing rat neuroepithelium (e.g., Nornes and Das, 1974; Altman and Bayer, 1982, 1984) and greatly resembles the staining patterns obtained in classical studies of rat neurogenesis using reducedsilver methods (Windle and Baxter, 1936a, b). It is noteworthy that all $3 \mathrm{NF}$ proteins are strongly argyrophilic (Gambetti et al., 1981; Autilio-Gambetti et al., 1986) and that NFs are the major neuronal structures stained by silver impregnation techniques (Boycott et al., 1961; Potter, 1971). The fibrillar patterns observed in early neurons (Windle and Baxter, 1936a, b) suggest that NF-M and NF-L exist in filamentous rather than unassembled form at E12.

\section{The spread of $N F$ protein expression in early rat neuroepithelium}

The micrographs in Figure 2 are reproduced in color because of the weak staining of E12 neurons by NF-M-specific mAbs, even when used undiluted. Figure 3,a-c, shows the dramatic increases in both intensity and extent of NF immunoreactivity at E13 (compare with Fig. 2). At E13, the NF-M-specific mAbs RMO108 and RMO93 continued to stain most of the structures 
shown in Figure 3, even after 1000-fold dilutions (e.g., Fig. 4b). Since the optimum dilution of these mAbs for continued staining in adult rat spinal cord was about 1:100 (Lee et al., 1987), NF-M quantities per unit volume of neuronal cytoplasm appeared to be close to adult levels by E13. Figure 3 also demonstrates the rostrocaudal gradient along the neuroepithelium of cells immunopositive for NF-M: neurons in the mesencephalon (Fig. $3 c$ ) stained intensely, while immunoreactivity became increasingly weaker, progressing to more caudal segments of the spinal cord (see tail segment of cord at the bottom of Fig. 3, $b$ and $c$ ). Arborizing branches of peripheral nerves filled with NF immunoreactivity were already prominent at E13 (see Fig. 3a), but structures in the forebrain (telencephalon), optic pouches, and eyes were completely negative (Fig. $3 c$ ).

\section{Phosphorylation of $N F-M$ during early stages of rat neurogenesis}

Figure 4 shows micrographs of E13 spinal cord stained using an NF-L-specific mAb (Fig. $4 a$ ) and mAbs specific for the partly $(\mathrm{P}[+]$; Fig. $4 b)$ or substantially $(\mathrm{P}[+++]$; Fig. $4, c, d)$ phosphorylated variants of NF-M. Similar neuronal populations were stained by each $\mathrm{mAb}$, but the distributions of immunoreactivities in these neurons were not the same. NF-L-specific mAbs stained throughout the E13 cells (Fig. 4a), whereas NF-M-specific mAbs of the $\mathrm{P}[+]$ type (e.g., RMO108 in Fig. $4 b$ ) stained axons and peripheral nerves more intensely than they did DRG and ventral horn perikarya. This staining asymmetry had not been observed with such mAbs in putative neurons of $E 12$ tissue (Fig. 2). It was even more apparent in preparations probed with $\mathrm{mAbs}$ recognizing extensively phosphorylated $(\mathrm{P}[+++])$ forms of NF-M (such as RMO45 in Fig. 4d), particularly upon dilution of such mAbs (Fig. $4 c$ ). Since $\mathrm{P}[+++] \mathrm{mAbs}$ had not stained E12 neurons, and an axonally biased distribution for $P[+]$ forms of NF-M was also absent, the data suggest the setting up of a proximodistal gradient of NF-M phosphorylation after a short delay (ca. $24 \mathrm{hr}$ ). These results also show that the adult pattern of progressive phosphorylation of NF-M during its passage from perikaryon to axon (Goldstein et al., 1987; Lee et al., 1987) is established very early in the motor and sensory neurons of developing rats.

\section{Biochemical demonstration that $N F-M$ is phosphorylated, but incompletely so, in newly formed rat neurons}

Figure 5 compares the SDS-PAGE and corresponding immunoblot patterns of proteins extracted from E13 rat embryos (Fig. 5 , lanes 1) with NFs purified from adult rat spinal cord before (Fig. 5, lanes 2) and after treatment with $E$. coli alkaline phosphatase for $36 \mathrm{~min}$ (Fig. 5, lanes 3) or $18 \mathrm{hr}$ (Fig. 5, lanes 4). Note that the apparent $M_{\mathrm{r}}$ of both NF-M and NF-H is reduced after removal of charged phosphate groups (see also Julien and Mushynski, 1982; Carden et al., 1985; Glicksman and Willard, 1985; Lee et al., 1986b, 1987; Shaw et al., 1986; Schmidt et al., 1987 ) and that 3 forms of NF-M, termed NF-Ma, NF-Mb, and NF-Mc by Lee et al. (1987), are generated in the process. In- cubation with $\mathrm{P}[+]$-type mAbs, such as RMO93, identified a doublet of immunoreactive bands in the E13 extract (Fig. 5b, lane 1) migrating at the level of NF-M in the adult rat NF standards (Fig. 5b, lanes 2-4). The top band of this doublet stained most intensely and migrated slightly more quickly than did NF-M in the adjacent, fully phosphorylated (i.e., untreated) standard (compare Fig. 5b, lanes 1 and 2). The more weakly stained band migrated at the level of extensively dephosphorylated NF-M in Figure $5 b$, lane 4 . The most extensively phosphorylated form of NF-M (NF-Ma; Lee et al., 1987), while readily apparent in the adult NF sample (Fig. $5 b$, lane 2), was absent from the E13 sample (Fig. 5b, lane 1). This explains the negative immunoblot results (not shown) obtained with mAbs specific for this NF-M isoform alone, such as RMO45 (defined as $\mathrm{P}[+++]$ type). Since RMO45 stained E13 axons in tissues, albeit weakly (e.g., Fig. $4 d$ ), we suggest that very small amounts of this protein, certainly less than is efficiently detectable by immunoblot, exist at this stage.

Antibodies to NF-L were negative on E13 blots, even though they stained a band at $M_{\mathrm{r}} 68,000$ in the NF standards (data not shown) and were strongly immunoreactive in tissue sections (Fig. $4 a$ ). This could be due to their low binding affinity for NF$\mathrm{L}$, as suggested by the fact that these mAbs generally required larger quantities of NF protein (by 10-fold) than did NF-Mspecific mAbs for immunoblot positivity (unpublished observations).

\section{First appearance of $\mathrm{NF}-\mathrm{H}$ and its phosphorylation characteristics in developing rat embryos}

Convincing NF-H-specific immunoreactivity was obtained at E15. Prior to this time, both frozen and Bouin's-fixed sections appeared negative with all $12 \mathrm{NF}-\mathrm{H}$-specific mAbs (Table 1), including those recognizing nonphosphorylated NF-H (i.e., P[-]type mAbs). Examples of NF-H-specific immunostaining in Bouin's-fixed sections of $E 15$ rat head and spinal cord are shown in Figures 6 and 7, respectively. To achieve any staining, it was necessary to use NF-H-specific mAbs neat, despite the fact that many of the same mAbs could be used at high dilutions (e.g., up to $1: 100,000)$ in adult rat spinal cord neurons and their processes (Goldstein et al., 1987; Lee et al., 1987). Despite this low-level expression, all 4 differentially phosphorylated states of NF-H $(\mathrm{P}[-], \mathrm{P}[+], \mathrm{P}[++]$, and $\mathrm{P}[+++]$; see Table 1 and Lee et al., 1987) were clearly detcctable at E15, even though each was localized to different, yet characteristic, regions of asymmetrical neurons. For example, $\mathrm{P}[-]$ forms of NF-H were observed only in cell bodies, such as the trigeminal ganglia (Fig. $6 e$ ), ventral horn motor neurons, DRG, and sympathetic ganglia (Fig. $7 d$ ). $\mathrm{P}[+]$ forms, on the other hand, were stained only faintly in perikarya, while being fairly abundant in proximal, as well as distal, nerve processes (Fig. 6f). Highly phosphorylated forms $(\mathrm{P}[++]$ and $\mathrm{P}[+++])$ of $\mathrm{NF}-\mathrm{H}$ appeared only in axons (Fig. $7 e$ ) and, moreover, were most strongly immunoreactive in distal rather than proximal portions of peripheral nerves (Fig. $7 f$ ). In CNS, both of these NF-H variants were barely detectable in

Figure 2. Distribution of NF-positive cells in E12 rat embryos revealed using mAbs to NF-M, the ABC technique, and 6- $\mu$ m-thick sagittal sections from the same paraffin-embedded, Bouin's-fixed embryo. Two $\mathrm{P}[+]$-type mAbs were used, RMO93 $(a, e, f)$ and RMO108 $(b, d, g-i)$. The section in $c$ was reacted with $\mathrm{RMO} 205$, a $\mathrm{P}[-]$-type, NF-H-specific mAb that stains adult neurons very weakly and serves here as a negative control. $e$ and $f$, Enlargements of the section in $a$; $h$, enlargement of $b$. The sections are counterstained with hematoxylin. The width of each photo represents approximately $2110(a-c)$ or $850 \mu \mathrm{m}(d-i)$. 


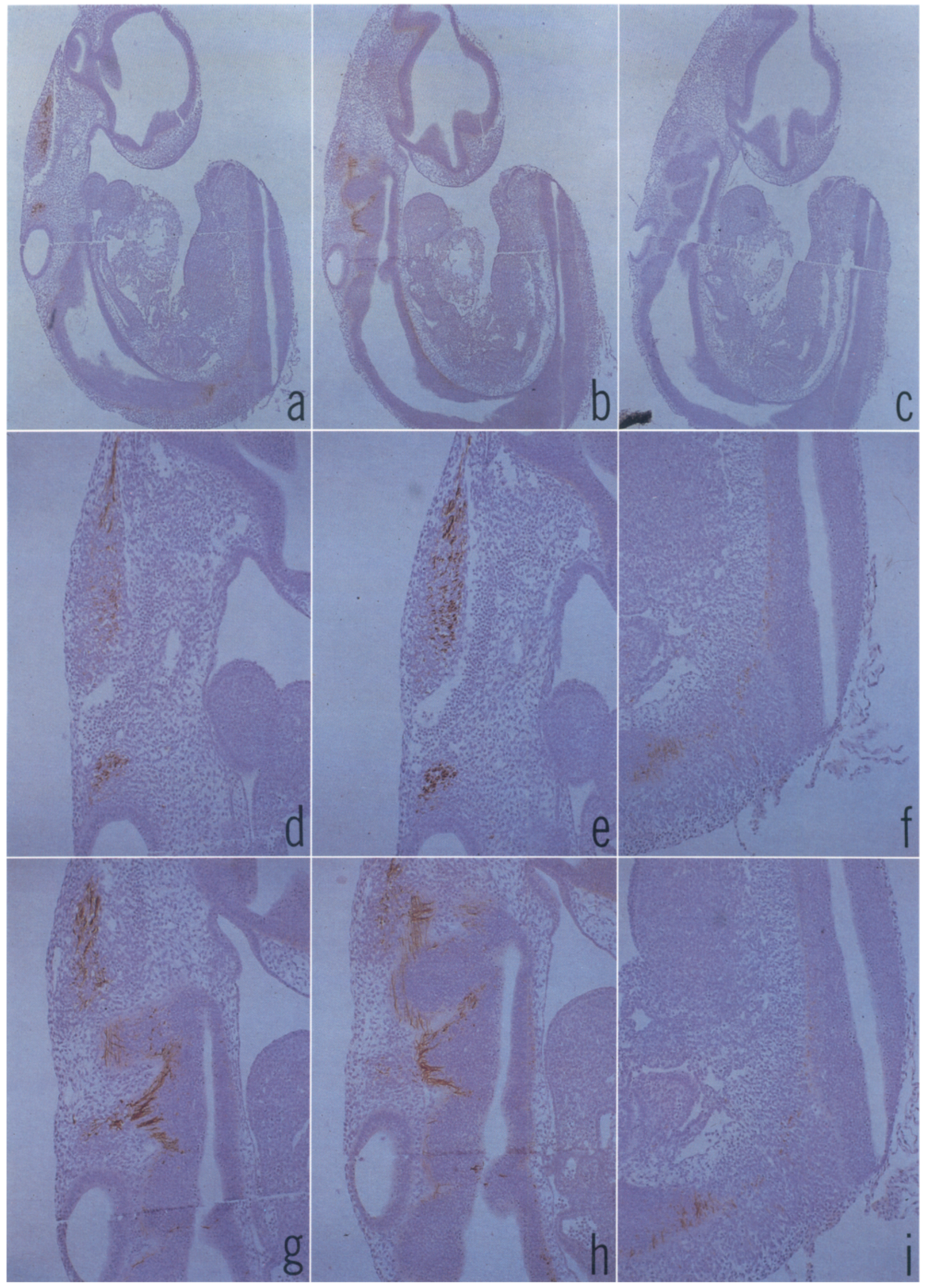



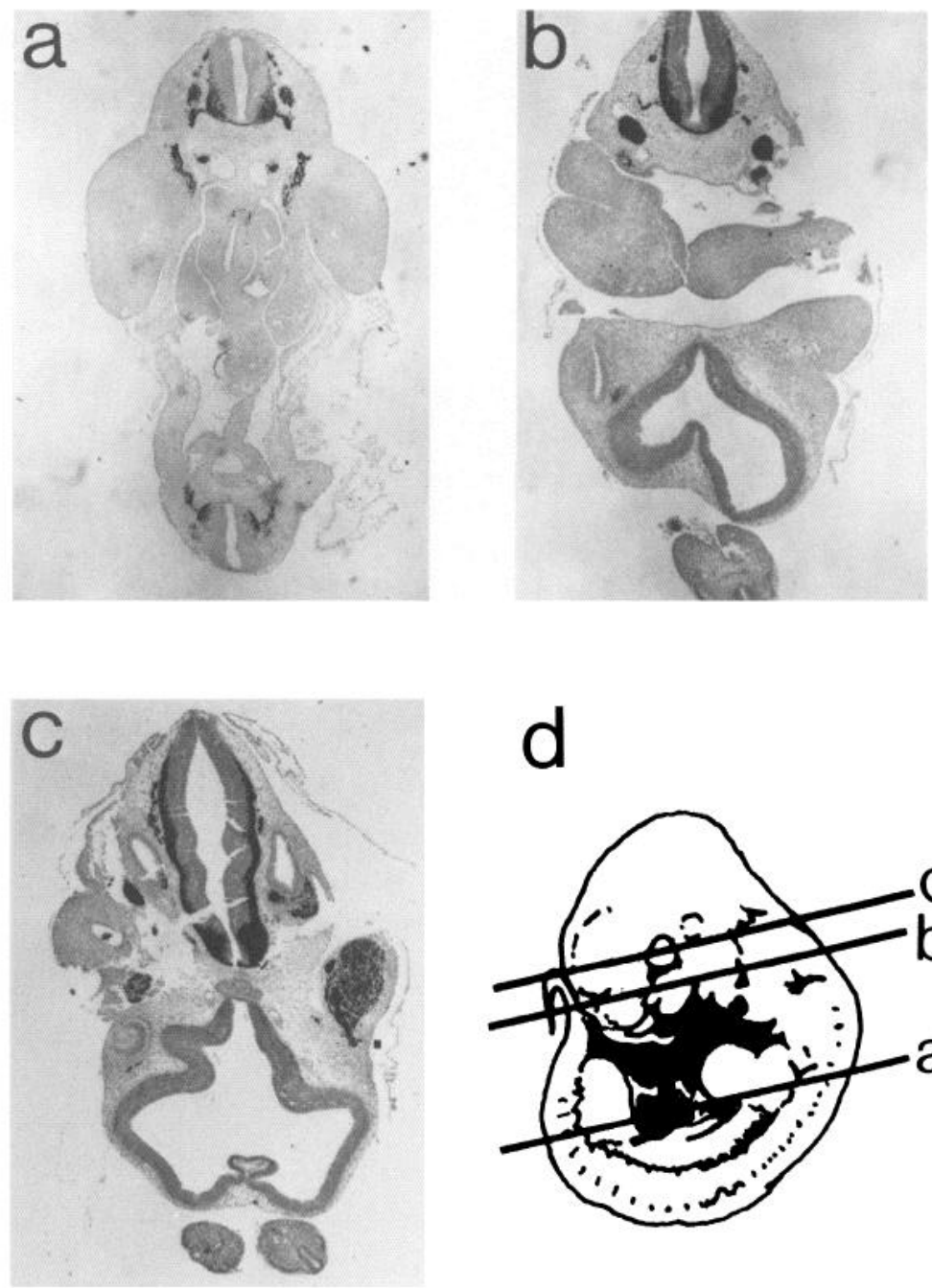

Figure 3. Distribution of NF immunoreactivity in E13 embryos revealed using an NF-M-specific mAb of the $\mathrm{P}[+]$ type (RMO93, undiluted). $d$, Diagram of the E13 embryo showing the level at which the sections in $a-c$ were taken. The sections are counterstained with hematoxylin. The width of each panel represents approximately $1760 \mu \mathrm{m}$.

axons (Fig. 7, $f$ and $e$, respectively), and only distal axons at the ventral outer surface of the white matter were stained (Fig. 7 , $e, f)$.

Low-level NF-H expression continued over the E15-E18 interval. By E17, the intensity of NF-H-specific immunostaining (Fig. 8, $a-c$ ) remained well below that of NF-M (Fig. 8, $d-h$ ), although certain types of epitopes became more extensively distributed. For example, $\mathrm{P}[-] \mathrm{mAbs}$ stained proximal axonal structures such as the dorsal root (Fig. $8 c$ ). $\mathrm{P}[+++]$-type mAbs also stained E17 neurons more extensively, with proximal axons, including CNS white matter starting to stain (Fig. $8 a$ ). Note that the immunostaining of white matter is roughly similar by these 2 kinds of mAbs (compare Fig. 8, $a$ and $c$ ), suggesting that there are roughly equal proportions of nonphosphorylated and highly modified forms of NF-H.

\section{Biochemical demonstration of NF-H phosphorylation in E17 rat embryos}

Figure 9 shows Western blots of E17 spinal cord extracts (lane 4 in each blot) compared to phosphorylated (untreated) and differentially dephosphorylated samples of adult rat NFs (lanes 1-3). Different types of NF-H-specific mAbs were tested, together with certain NF-M-specific mAbs as controls. The first blot (Fig. 9A) shows a single heavy band in the E17 extract (lane 4) comigrating with highly phosphorylated NF-M (the NF-Ma isoform; Lee et al., 1987) in the adult NF standard (lane 1). Since the mAb used was of the P[ind] type, this result shows that most of the NF-M at E17 exists in the $\mathrm{P}[+++]$ state. The same conclusion can be derived from the results in Figure $9 B$ which was stained with $\mathrm{mAb}$ specific for this isoform of NF-M.

The presence of NF-H at E17 is clearly demonstrated in Figure $9 C$ using a mAb of the $\mathrm{P}[+]$ type. The major immunoreactive band in the E17 extract (lane 4) migrates at the same position as highly (lane 1) and partially (lane 2) phosphorylated forms of NF-H. Note that the $\mathrm{P}[+] \mathrm{mAb}$ fails to stain extensively dephosphorylated NF-H (lane 3 ). This not only shows the presence of NF-H at E17 (confirming mAb specificity in fetal tissue), but also that NF-H is at least partly phosphorylated at this time point. Given this strong immunoblotting result, it was not surprising to find that mAbs specific for nonphosphorylated NF-H (Fig. 9D) also reacted at E17 (lane 4), detecting bands ranging from apparent $M_{\mathrm{r}} 180,000$ to 200,000 , as they do in adult nervous tissue (Lee et al., 1986b). However, the fact that quite strong staining was obtained suggested that a larger amount of NF-H exists in the P[-] form at E17 (see also Lee et al., 1987) than in adult rats (Lee et al., 1986b). This might be explained by the fact that $\mathrm{P}[+++] \mathrm{mAbs}$ were negative against $\mathrm{E} 17$ extracts, showing that while large quantities of NF-H were phosphorylated to the $\mathrm{P}[+]$ form at $\mathrm{E} 17$, this phosphorylation was 
incomplete at the E17 stage of neuronal development. While histochemical results suggested the presence of NF-H at E15 (Figs. 6, 7), immunoblots of such tissue were not convincingly reactive with $\mathrm{NF}-\mathrm{H}$-specific mAbs, perhaps because of the very low levels of NF-H expressed at this time.

\section{$N F$ protein expression and phosphorylation during later development of rat embryos}

NF-L and NF-M appeared in cells of the developing rat nervous system soon after the point of commitment to a neuronal phenotype, as defined by studies of neurogenesis (e.g., Nornes and Das, 1974; Altman and Bayer, 1982, 1984, 1986). Moreover, levels of immunoreactivity to these 2 NF subunits and the patterns of NF-M phosphorylation approached those of adult rats around E15. NF-H, on the other hand, was first expressed at E15 and remained at low levels in neurons for a considerable time thereafter. E19 was the first time point at which NF-H immunoreactivity was consistently detectable in every section tested from numerous blocks of Bouin's-fixed embryos (e.g., Fig. 10). However, NF-H-specific mAb dilutions continued to be well below those that effectively stained adult tissue. Furthermore, subtle differences remained between the distribution patterns of non- and poorly phosphorylated NF-H isoforms at E19 compared to adult. For example, undiluted $\mathrm{P}[-] \mathrm{mAbs}$ continued to stain proximal axons (Fig. 10b), including spinal cord white matter, although 100 -fold dilution eliminated this reactivity (Fig 10a) without much affecting the intensity of perikaryal staining. Axonal phosphorylation of NF-H appeared quite advanced by $\mathrm{E} 19$, with $\mathrm{P}[+], \mathrm{P}[++]$, and $\mathrm{P}[+++]$ types of $\mathrm{mAb}$ all staining axonal structures nearly evenly and quite intensely (Fig. 10, $e-g$, respectively). It is noteworthy that regions reacting with $\mathrm{mAbs}$ against phosphorylated NFs began to immunoreact poorly with $\mathrm{P}[\mathrm{ind}]$-type mAbs. Indeed, the pattern in Figure $10 c$ (by a $\mathrm{P}$ [ind] $\mathrm{mAb}$ ) is reminiscent of that obtained using a $\mathrm{P}[-] \mathrm{mAb}$ in a nearly adjacent section (Fig. 10b). This might suggest that NF phosphorylation masks P[ind]-type epitopes in Bouin's-fixed tissue.

Since levels of NF-H had not reached those of adult by E19, immunohistochemical studies were continued by examining neonatal rats (postnatal day 0, or PND0) and PND21 spinal cord/DRG preparations (data not shown). Surprisingly, it remained necessary at E21, for example, to use NF-H-specific $\mathrm{mAbs}$ at dilutions well below those useful for optimal staining of adult tissue. This shows that NF-H levels continue to increase in neurons for several weeks of postnatal development, accentuating the difference between the regulatory mechanisms that govern expression of NF-M and NF-L, on the one hand, and of NF-H on the other.

\section{Discussion}

Instrumental to these studies was the well-defined library of mAbs capable of distinguishing each rat NF subunit at various epitopes and, in the cases of NF-M and NF-H, in differentially phosphorylated states (Table 1 and Lee et al., 1987). Application of these probes to serial frozen or paraffin-embedded sections of rat embryos enabled a systematic and comparative study to be made of NF subunit expression and the accompanying phosphorylation of NF-M and NF-H between E12 and PND21. The scope of the studies was extensive, but was necessary in order to deal with some inherent problems of NF immunoreactivity, such as variable antigenic preservation of certain NF epitopes after tissue fixation (e.g., Hickey et al., 1983; Trojanowski et al.,
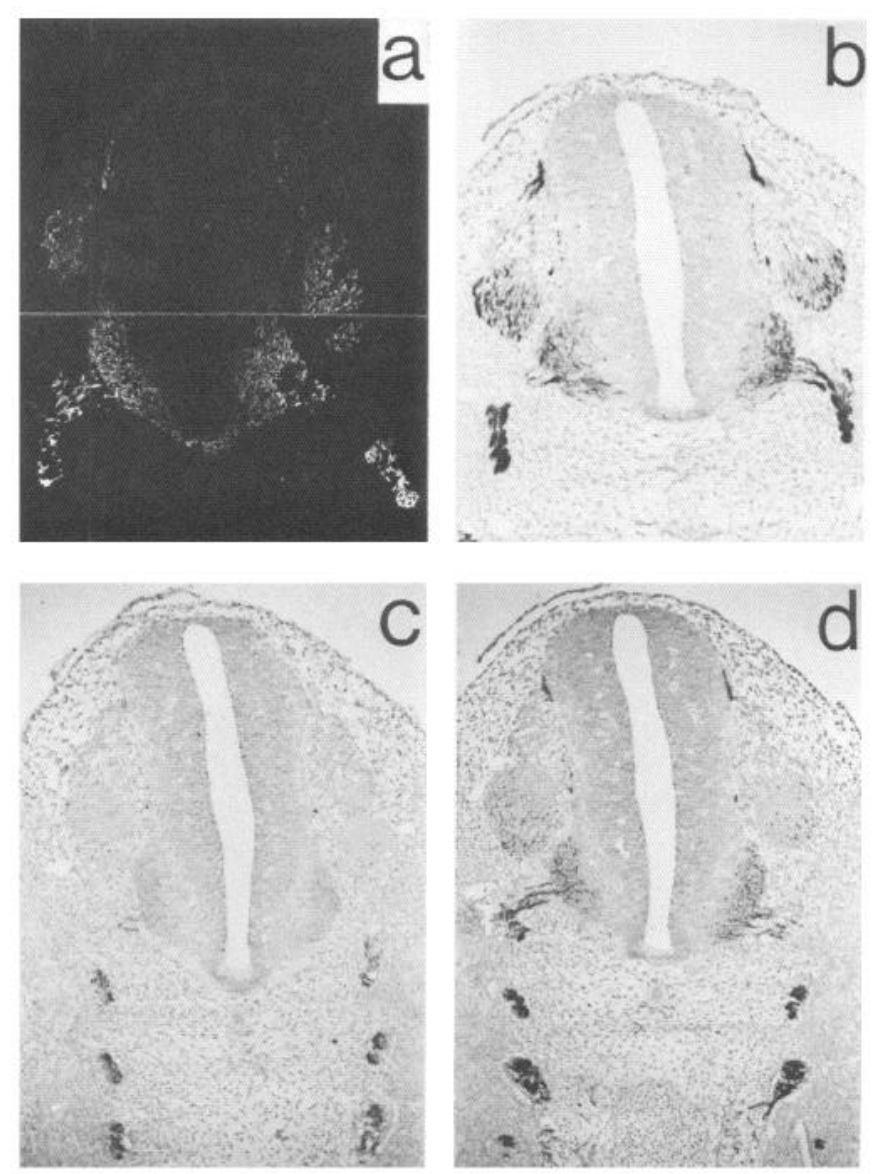

Figure 4. NF immunoreactivity in the spinal cord and DRG of E13 embryos, showing that NF-M is expressed in several differentially phosphorylated isoforms by this developmental time point. RMS21 (NF-Lspecific) was used for the fluorescence micrograph in $a$, while RMO108 $(\mathrm{P}[+]$, NF-M-specific), diluted $\times 1000$, was used for the ABC-stained section in $b$. Note that axons are stained more strongly than perikarya. $c$ and $d$, Another NF-M-specific mAb of the $\mathrm{P}[+++]$ type (RMO45) was used. When used neat $(d)$, axons are strongly stained, while perikarya are almost unstained. Dilution of this $\mathrm{mAb} \times 10(\mathrm{c})$ all but abolishes the perikaryal immunoreactivity, while axons continue to be stained quite strongly. The sections in $b-d$ were counterstained with hematoxylin. The width of each photo represents approximately $700 \mu \mathrm{m}$.

$1983,1985,1986)$ and the substantial effects of phosphorylation upon the antigenicity of both NF-M and NF-H (e.g., Sternberger and Sternberger, 1983; Wong et al., 1984; Bennett and DiLullo, 1985b; Carden et al., 1985; Glicksman and Willard, 1985; Dahl et al., 1986; Lee et al., 1986a, b, 1987; Shaw et al., 1986; Goldstein et al., 1987; Schmidt et al., 1987). Further, it was deemed necessary to verify results of tissue staining using immunoblots, since antibodies to NFs, even monoclonals, can cross-react among subunits (particularly NF-M and NF-H) (e.g., Anderton et al., 1980; Dahl, 1980; Schlaepfer et al., 1981; Wood and Anderton, 1981; Calvert and Anderton, 1982; Lee et al., 1982, 1986a, b, 1987; Prochiantz et al., 1982; Debus et al., 1983; Shaw et al., 1984, 1986; Carden et al., 1985) or recognize other proteins (Lee et al., 1984; Balkema and Drager, 1985; Wood et al., 1985; Luca et al., 1986; Miller et al., 1986), as well as switch subunit specificities between species (Shaw et al., 1984; Lee et al., 1986a; Schmidt et al., 1987). This latter problem was eliminated here by the use of rat proteins as immunogens to raise and screen the mAbs (Lee et al., 1987). 
Figure 5. Immunoblot evidence supports the existence of a phosphorylated form of NF-M in E13 embryos and simultaneously establishes $\mathrm{mAb}$ specificity. $a$, A Coomassie-stained gel. $b$, The corresponding immunoblot after immunoreaction with RMO93, a $\mathrm{P}[+]$-type, NF-M-specific mAb. $a$ and $b$, Lane 1 contained a urea/SDS-soluble extract from whole E13 rat embryos (the load here represents approximately one-fifth of the total of such proteins from a single embyro). Lanes 2-4 contained NFs purified from adult rat spinal cord and exposed to $E$. coli alkaline phosphatase for different times: lane 2, 0 time; lane $3,36 \mathrm{~min}$; lane 4 , overnight ( $>20 \mathrm{hr}$ ).

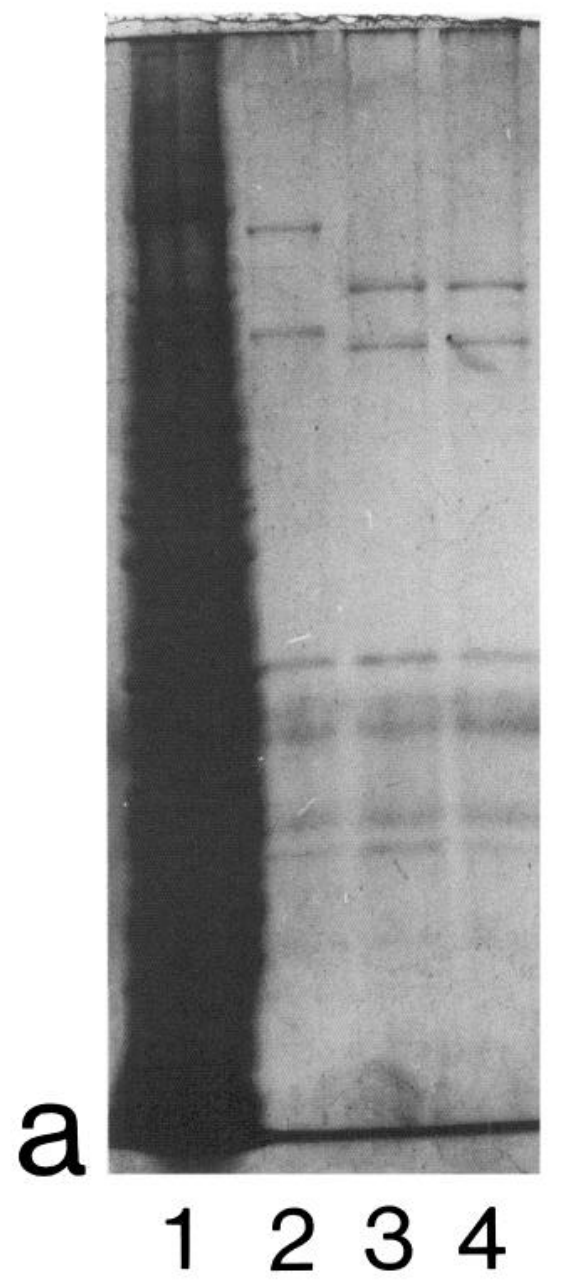

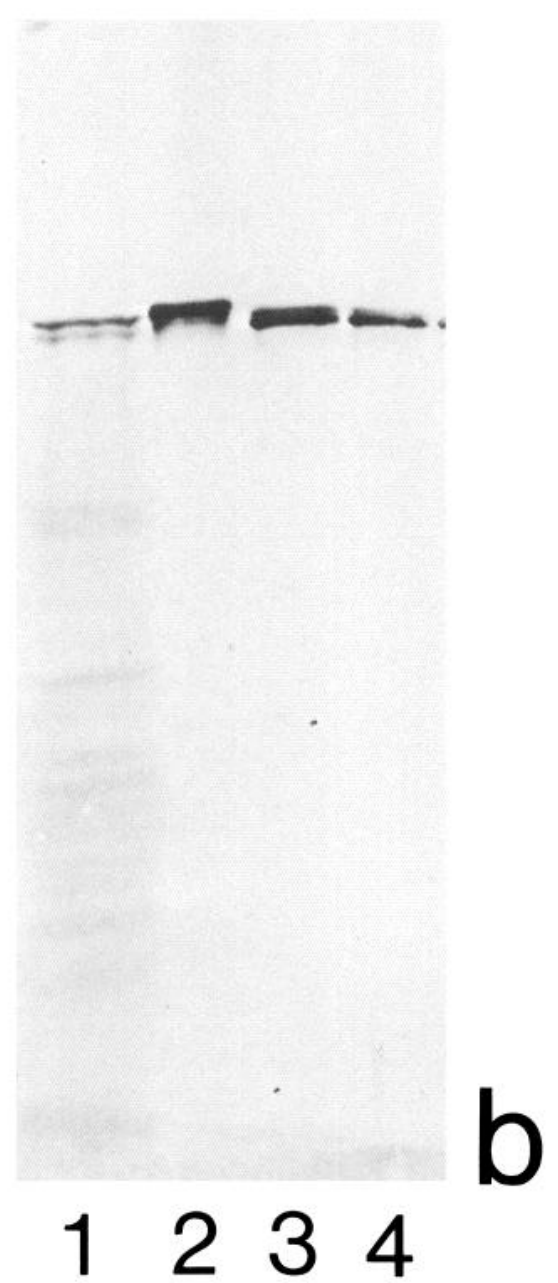

looked NF-H expression in nascent form because of the technical difficulties associated with its demonstration using conventional antibodies or SDS-PAGE. All neurons examined in the present study, despite differences in the days on which they were first produced, expressed the "immature" form of NFs prior to going on to express NF-H. Indeed, the previous studies noted the same features despite their examination of NF subunit expression in the rabbit nervous system (Willard and Simon, 1983) or in regions of the rat nervous system in which neurogenesis occurs much later than in the early neural tube structures studied here. Hence, it would appear that delayed NF-H expression is characteristic during develoment of the cytoskeleton in most, if not all, mammalian neurons, regardless of species or differences in the timing of the initial onset of neurogenesis.

Expression of an incomplete set of NF proteins (i.e., NF-M and NF-L, but not NF-H) as a component of the early neuronal cytoskeleton poses interesting questions about the control of NF gene expression in developing neurons. NF-L and NF-M genes seem to be tightly linked, since both were always present in the same cells and parts of cells. Moreover, both subunits appeared in unison and attained adult levels of immunoreactivity together and within $1 \mathrm{~d}$. A consequence of such gene linkage might be that NF-M and NF-L are obligatory components of NFs in vivo, despite the fact that purified NF-L can assemble into full-length, intermediate-sized filaments in vitro (e.g., Geisler and Weber, 1981; Liem and Hutchison, 1982; Zackroff et al., 1982; Lifsics
1984; Harry et al., 1985; Nona et al., 1985). However, this study lays to rest the idea that this previous work might have overunits.

Delayed expression of NF-H has been noted previously, using subunit-specific antisera and/or SDS-PAGE methods (Shaw and Weber, 1982, 1983; Willard and Simon, 1983; Pachter and Liem, 

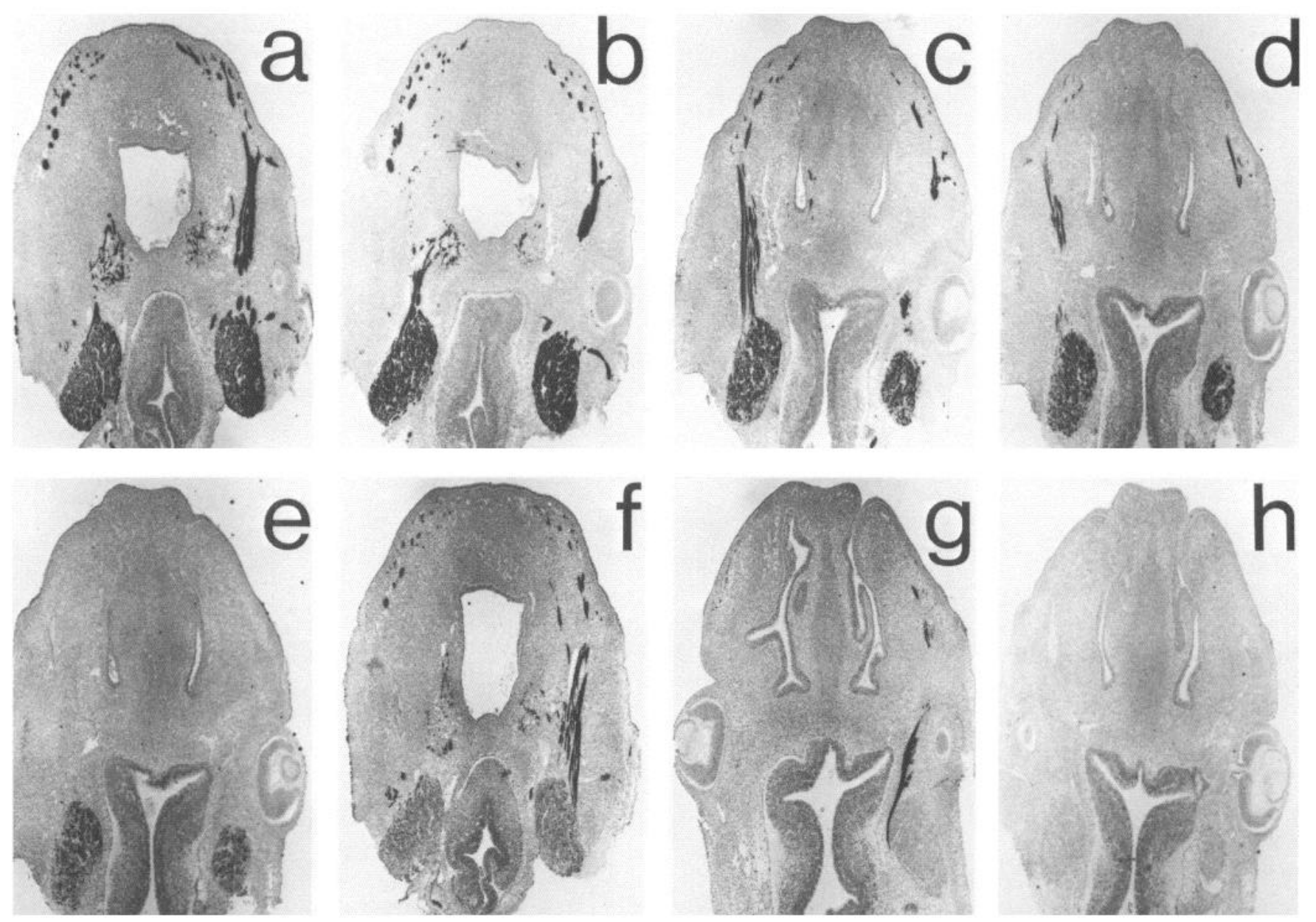

Figure 6. NF immunoreactivity in the $\mathrm{E} 15$ rat embryo head using the ABC visualization method. Antibodies and specificities follow: $a$, RMO108, $\mathrm{P}[+]$ : NF-M-specific; $b$, RMO93, P[+]: NF-M-specific; $c$, RMO3, P[ind-periph]: NF-M-specific; $d$, RMdO10, P[ind-rod]: NF-M-specific; $e$, RMdO9, $\mathrm{P}[-]$ : NF-H-specific; $f$, Ta51, P[+]: NF-H-specific; $g$, RMO45, P[+++]: NF-M-specific; $h$, negative control (unfused myeloma culture supernatant). Perikarya in trigeminal ganglia and nerves arising from it, as well as other peripheral nerve ramifications, are strongly stained in $a-d$, whereas the $\mathrm{P}[+++]$-type, NF-M-specific mAb $(g)$ stains only axons, and the $\mathrm{P}[-]$-type mAb stains only perikarya. Ta51 $(f)$, which was used here diluted $\times 10$, recognizes $\mathrm{P}[+]$ forms of NF-H and stains axons strongly but perikarya very weakly. No antibody stained the eye or midbrain at E15. The sections are counterstained with hematoxylin. The width of each photo represents approximately $780 \mu \mathrm{m}$.

and Williams, 1984; Minami et al., 1984). Linkage of NF-M and NF-L genes would also suggest that the same signal(s) induces them in newly formed neurons. One such signal could be related to the generalized induction of neuron-specific genes upon commitment to a neuronal phenotype. Alternatively, synthesis of NF-M and NF-L might be a response to signals associated with the extension of actively, and rapidly, elongating neurites, in which case the "immature" form of NFs could be required for supporting these structures and/or this event.

Conversion of "immature" NFs into a "mature" form (i.e., containing NF-H) is a very slow process during neuronal development and maturation. Indeed, the low level of NF-H expression by early neurons has masked our ability to be precise about the time point at which this subunit is first synthesized by embryonic rat neurons. It is clear, nevertheless, that amounts of NF-H remained well below those of either NF-M or of NF-L for considerable lengths of time. This very slow increase in NF-H synthesis during neuronal development has not been strongly emphasized before (e.g., Shaw and Weber, 1982; Willard and Simon, 1983; Pachter and Liem, 1984; Harry et al., 1985; Nona et al., 1985), even though most data support this observation. Metabolic labeling studies of perinatal and early postnatal rat spinal cord tissues also support the idea that NF-H increases slowly and steadily compared to NF-M and NF-L over long time periods. Smith et al. (1984) found that synthesis of all $3 \mathrm{NF}$ components became comparable to adult turnover rates only after $60 \mathrm{~d}$ of postnatal development by rats.

Clearly, regulation of the NF-H gene differs from the mechanism(s) that governs NF-M and NF-L genes. The delay in appearance of NF-H until E15 and, moreover, the expression of this subunit only in neurons with well-established axons suggest that its recruitment into the neuronal cytoskeleton occurs after synaptogenesis. For example, Dennis et al. (1981) showed that active neuromuscular junctions are formed around E15, the time when spinal cord motor neurons first express NF-H. These observations suggest that some external factor might be important in the induction of the NF-H gene (or translation of pre-existing mRNA). Indeed, some neurons in tissue culture express abundant quantities of NF-M and NF-L, but little, if any, NF-H (e.g., Lee, 1985; Shaw et al., 1985), a feature related, perhaps, to the absence of external influence by other cell types (see also Prochiantz et al., 1982). One external signal could be 


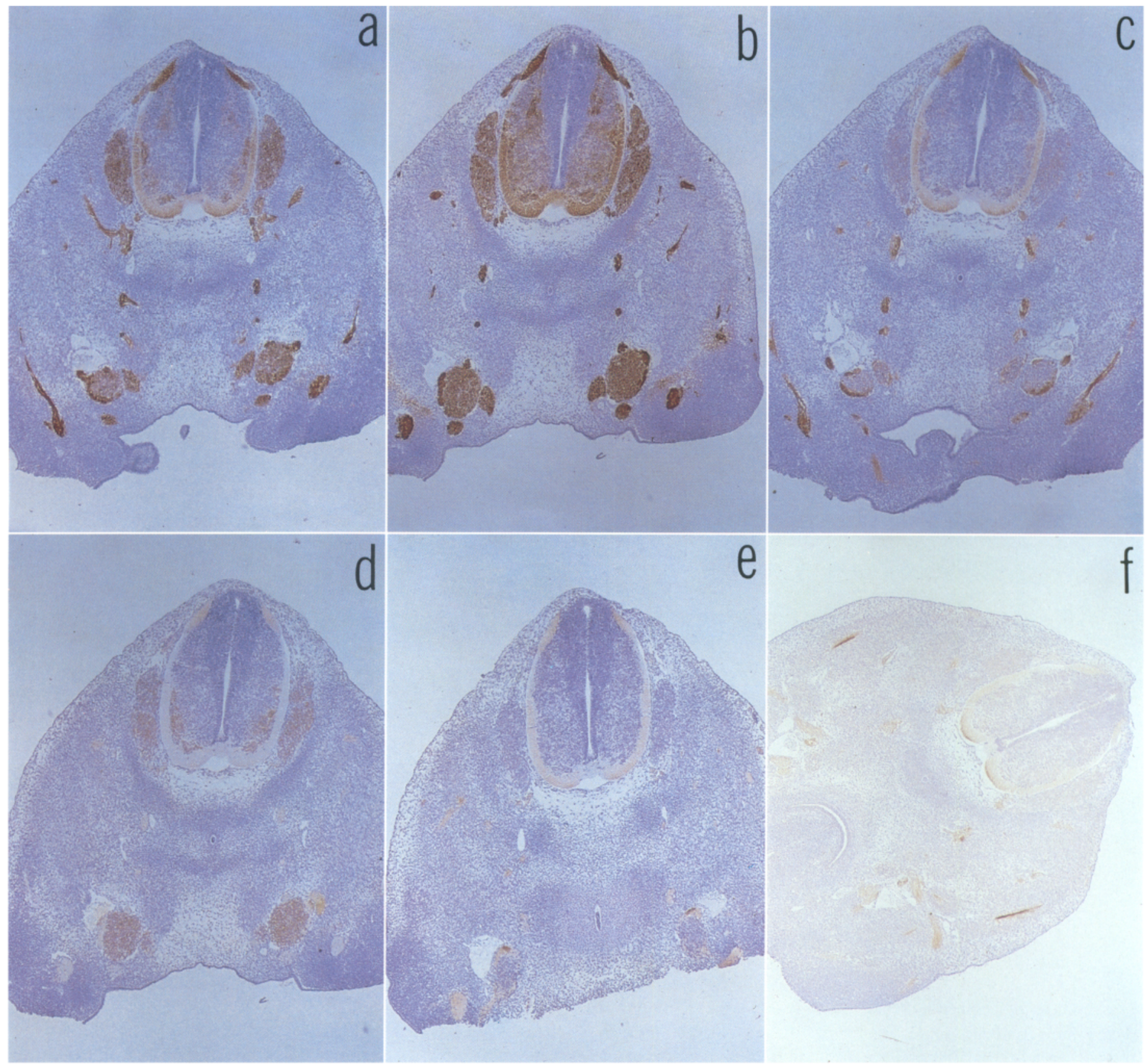

Figure 7. NF-H can be detected, but at very low levels compared wtih NF-M staining in E15 spinal cord. Antibodies and their specificities follow: $a$, RMO93, $\mathrm{P}[+]$ : NF-M-specific; RMO108, $\mathrm{P}[+]$ : NF-M-specific; $c$, RMO45, $\mathrm{P}[+++]$ : NF-M-specific; $d$, RMdT2, $\mathrm{P}[-]$ : NF-H-specific; $e, \mathrm{RMO} 24$, $\mathrm{P}[+++]$ : NF-H-specific; $f$, RMO217, P[++]: NF-H-specific. RMO93 (a) was used diluted $\times 1000$ and RMdT2 $(d)$ was diluted $\times 100$. NF-Hspecific mAbs react weakly with perikarya $(\mathrm{P}[-])$ or axons $(\mathrm{P}[++]$ and $\mathrm{P}[+++])$, but in many other E15 embryo preparations they failed to stain at levels of intensity like those shown here. The sections are counterstained with hematoxylin. The width of each photo represents approximately $760 \mu \mathrm{m}$.

a substance secreted by target cells, taken up at synapses, and retrogradely transported, such as NGF. Certainly, NGF induces increased expression of NF proteins by neurons cultured in vitro (Lee, 1985). Alternatively, a signal for NF-H gene induction might derive from an intrinsic ability of neurons to detect functional contacts.

Conversion of "immature" NFs by nerve cells developing in vivo to "mature" forms via the addition of NF-H appears to be a fairly generalized phenomenon, although certain brain neurons may express NF-M and NF-L, but little or no NF-H, even in adult rats (Shaw et al., 1981; Shaw and Weber, 1982). Furthermore, filaments isolated from rat brain may contain less NF-H, as compared to NF-M and NF-L, than NFs isolated from peripheral nerve or spinal cord of the same rats (unpublished observations). Thus, certain neurons might continue to express into adulthood the "immature" form of NFs characteristic of cells having relatively plastic neurites typical of developmental states. Indeed, the retention of "immature" NFs may be reflective of a continued plastic state in neurons that are able to remodel their synapses and/or neuritic circuitries, as may be 

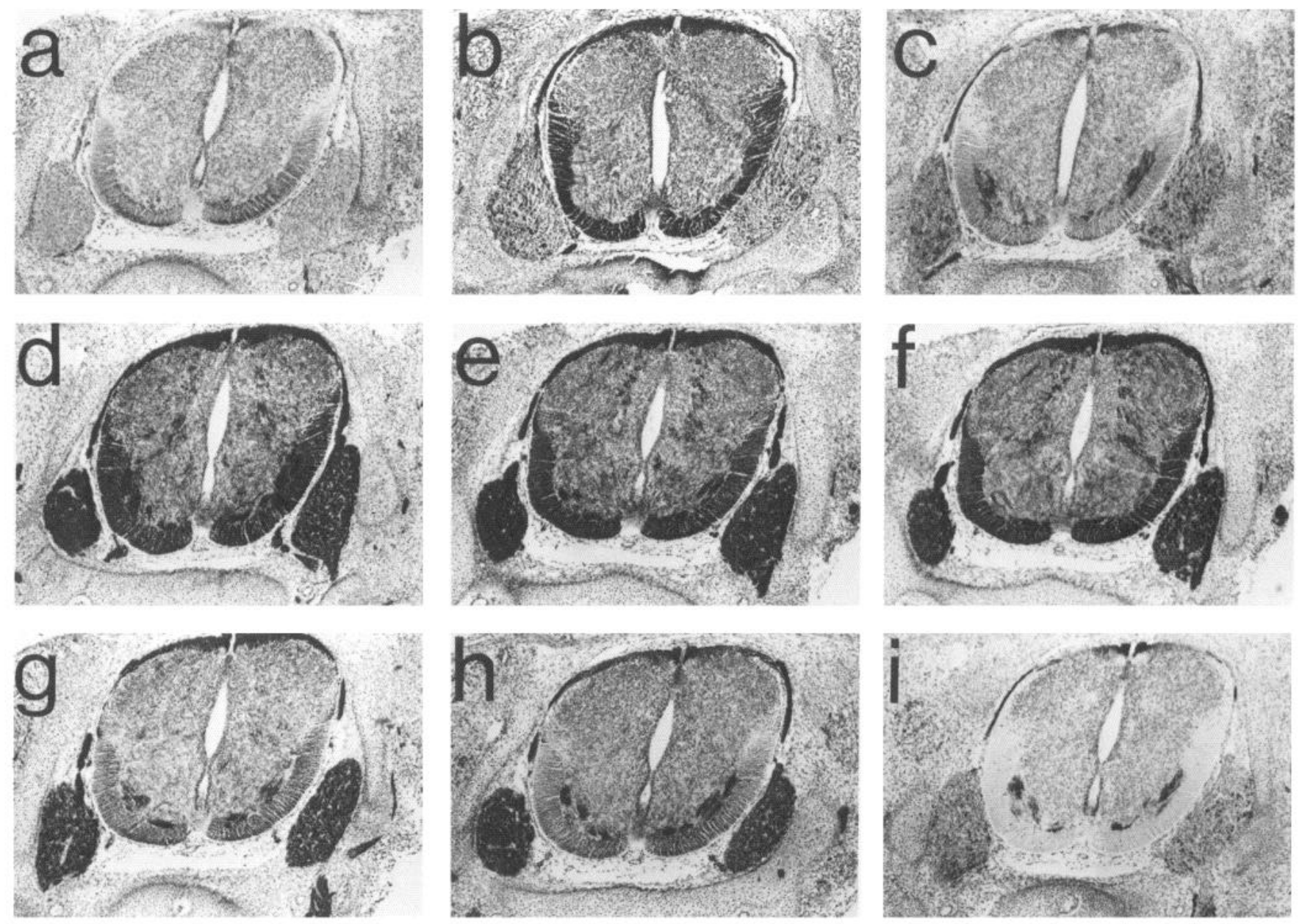

Figure 8. NF immunoreactivity in the E17 rat spinal cord and DRG. Antibodies and specificities follow: $a, \mathrm{RMO} 24, \mathrm{P}[+++]: \mathrm{NF}-\mathrm{H} ; b$, Ta51, $\mathrm{P}[+]$ : NF-H; $c$, RMdO9, P[-]: NF-H; $d$, RMdO4, P[+]: NF-M; $e$, RMO93, P[+]: NF-M; $f$, RMO108, P[+]: NF-M; $g$, RMO3, P[ind-periph]: NF-M; $h$, RMdO10, P[ind-rod]: NF-M; $i$, RMS12, P[ind]: NF-L. Note the weak immunoreactivity of the P[-] and P[+++] NF-H-specific mAbs in panels $a$ and $c$, respectively. The sections are counterstained with hematoxylin. The width of each photo represents approximately $1000 \mu \mathrm{m}$.

required of some brain neurons in order to accommodate a complex memory function.

\section{Phosphorylation of NFs during development and maturation}

Monoclonal antibodies distinguishing NF-H and NF-M in differentially phosphorylated states were used in this study, those against NF-M being the first such mAbs available (Lee et al., 1987). Indeed, these latter mAbs allowed us to demonstrate that, from the outset of synthesis at E12, NF-M is rapidly, though only partially $(\mathrm{P}[+])$, phosphorylated throughout the newly formed neurons, including their perikarya. Complete phosphorylation of NF-M to generate $\mathrm{P}[+++]$ forms takes place only after a further day in vivo, and occurs only in axons. These findings suggest that the kinase(s) responsible for extensive NF-M phosphorylation may be (1) absent or inactive at E12, (2) only present and/or active in axons, or (3) slow-acting.

Slow phosphorylation of NF-M has been indicated by ${ }^{32} \mathrm{P}-$ labeling of cultured chick (Bennett and DiLullo, 1985b) and rat (Black et al., 1986) neurons. Similar studies in adult rat nerves in vivo (Komiya et al., 1986a, b), also suggest slow rates for the complete phosphorylation of NF-M, as well as for NF-H. Nevertheless, a slow time course for the extensive phosphorylation of NFs is puzzling, since kinetics of kinase reactions in vitro are rapid (e.g., Nestler and Greengard, 1984). Perhaps the progres- sive addition of phosphate to NF proteins decreases their ability to accept subsequent modification, thus slowing the overall rate of complete phosphorylation. Alternatively, different sequences in the NF-M polypeptide might have different affinities for accepting phosphate groups from kinase(s), such that some sites would be phosphorylated only slowly. A third explanation could be that there is regionally dependent activation of NF-directed kinase(s). Such a mechanism might explain both the apparent slow rates and the axonal specificity of complete NF phosphorylation. One way in which NF-directed kinase activity might be modulated regionally would be if it depended on local conditions, such as ionic composition and/or $\mathrm{pH}$. This possibility would not necessarily require the activation of separate kinases in different regions along the neuroaxis, and it might also allow a single kinase to phosphorylate both the NF-M and NF-H subunits. Further, it might explain why it is difficult to demonstrate a gradient of immunoreactivity to $\mathrm{P}[+++]$-type epitopes along adult axons. The patterns in adult nerves (e.g., Lee et al., 1987) suggest that NF-M and NF-H become extensively phosphorylated soon after entering the axon (see also Toyoshima et al., 1984, 1985; Komyia et al., 1986a, b) and remain so during the transit of NFs along these highly asymmetric structures.

If local conditions do influence kinase activity, this does not 
Figure 9. Immunoblotting of E17 embryonic protein extracts (SDS/urea) using different $\mathrm{mAbs}$ demonstrates the existence at this developmental time point of highly phosphorylated $(\mathrm{P}[+++])$ NF-M and differentially phosphorylated isoforms of NF-H. Lanes 1-3 in each blot contain NF standards identical to those shown in lanes 2-4 of Figure 5, except that the one in lane 2 was only exposed to phosphatase for $12 \mathrm{~min}$. The protein extract from E17 rat spinal cord was loaded in lane 4 of each blot. Antibodies used to stain each blot are indicated. The whole blot for RMdO10 staining and lanes $1-3$ of the RMdO9 blot were incubated with a secondary antibody conjugated to peroxidase and developed with 4-chloronaphthol, whereas for the RMO55 and Ta51 blots, as well as in lane 4 of the RMdO9 blot, immunoreactivity was visualized with the more sensitive PAP method.

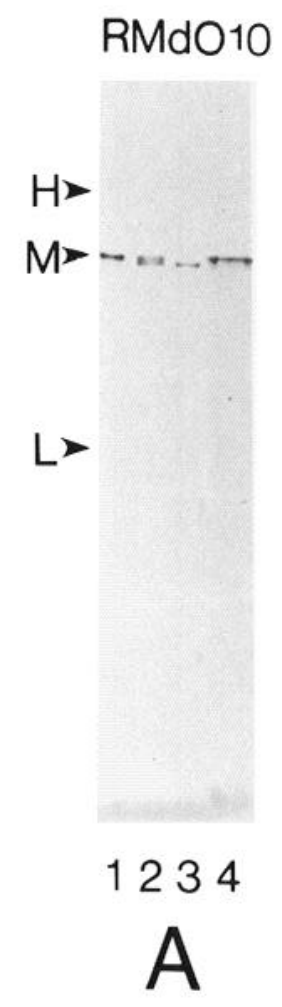

Ta51
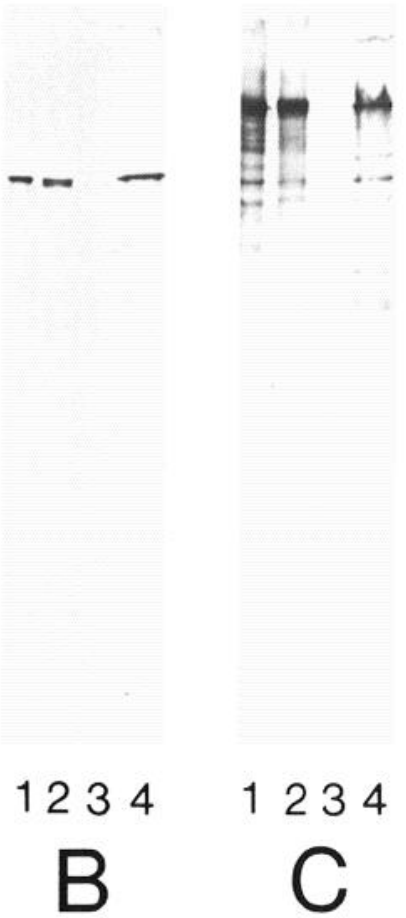

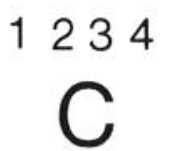

RMdO9

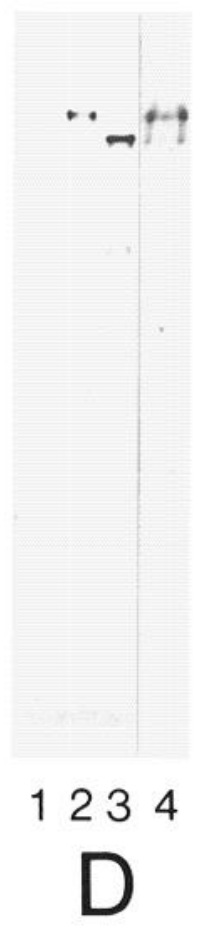

necessarily mean that $\mathrm{P}[+++]$ epitopes cannot be produced in perikarya under any circumstances, but only that the reaction rate is likely to be negligible under normal conditions. NFs would normally be removed from the perikarya into axons at adult rates of axonal transport (Hoffman and Lasek, 1975; Willard and Hulebak, 1977) before the kinase(s) had been allowed sufficient time to complete NF phosphorylation. A prediction from this schema would be that interruptions of axonal transport might increase the perikaryal phosphorylation of NFs. Indeed, abnormal perikaryal phosphorylation of NFs has been observed after their accumulation at this location during aluminum intoxication (Troncoso et al., 1986), as well as in transected nerves (Drager and Hofbauer, 1984; Goldstein et al., 1987), both situations being associated with decreased NF transport (Bizzi et al., 1984; Hoffman et al., 1985b; Troncoso et al., 1985). An alternative explanation for abnormal perikaryal phosphorylation under these circumstances might be that both kinds of insult to the neuron alter the perikaryal microenvironment sufficiently to activate NF kinase(s) abnormally.

The prolonged time course over which the accumulation of phosphorylated NF-H occurred in maturing axons paralleled that of the decrease in NF transport rate described by Hoffman et al. (1983) and Willard and Simon (1983), and the related phenomenon of growth in the caliber of axons (Hoffman et al., $1985 \mathrm{a}, \mathrm{b})$. This might suggest a link between the expression of the "mature" form of NFs and these events, particularly with respect to NF-H phosphorylation. Presumably, the radial growth of axons requires that fewer NFs leave a particular point than had entered it. This is the same as suggesting a gradient of transport rates along the axon. A similar gradient of NF-H phosphorylation would be predicted if phosphorylation of NF-H were to mediate the slowing of the NF transport rate. Indeed, this view is supported by our E15 data, which suggest that NF-H is more phosphorylated in distal than in proximal axonal seg- ments. The fact that such gradients of NF-H phosphorylation along axons cannot be demonstrated convincingly in adults (Lee et al., 1987) except, perhaps, for their initial segments (Lee et al., 1986b), is consistent with constant rates of slow NF transport in such axons (Hoffman and Lasek, 1975; Willard and Hulebak, 1977).

The hypothesis that NF-H phosphorylation progressively diminishes the rate of axonal transport would lead to the prediction that admixtures of differentially phosphorylated NFs would display a range of transport rates, thus explaining the observation of a broadened wave of pulse-labeled NFs traveling along axons during axonal maturation (Hoffman et al., 1983). This interpretation is, of course, dependent upon the ability of individual NFs, or small clusters thereof, to move independently in axons instead of as part of a large cross-bridged latticework. In fact, some degree of differential NF movement (Nixon and Logvinenko, 1986) appears necessary, even in adult myelinated nerves, in order to explain the movement of NFs through nodes of Ranvier, where both fiber diameter and numbers of NFs are reduced by over $50 \%$ compared to in the internodal segments.

A possible interpretation of the function of NF-H phosphorylation-bearing in mind the location of phosphorylation sites on the projecting domains of NF-H (Julien and Mushynski, 1983; Carden et al., 1985; Eagles et al., 1985; Geisler et al., 1985 -is that the highly charged phosphate groups tend to repel, rather than mediate, a cohesive interaction (P. A. M. Eagles, personal communications). This does not dispute the localization of NF-H within lateral "projections" on NFs (Hirokawa et al., 1984), but it does question the nature and stability of interactions between the "projections" of adjacent NFs. In fact, the hypothesis that extensive NF-H phosphorylation results in repulsion of adjacent filaments to which they are attached could explain previous observations that are not in full accord with the concept of a rigid cross-linking or cross-bridging of NFs by 

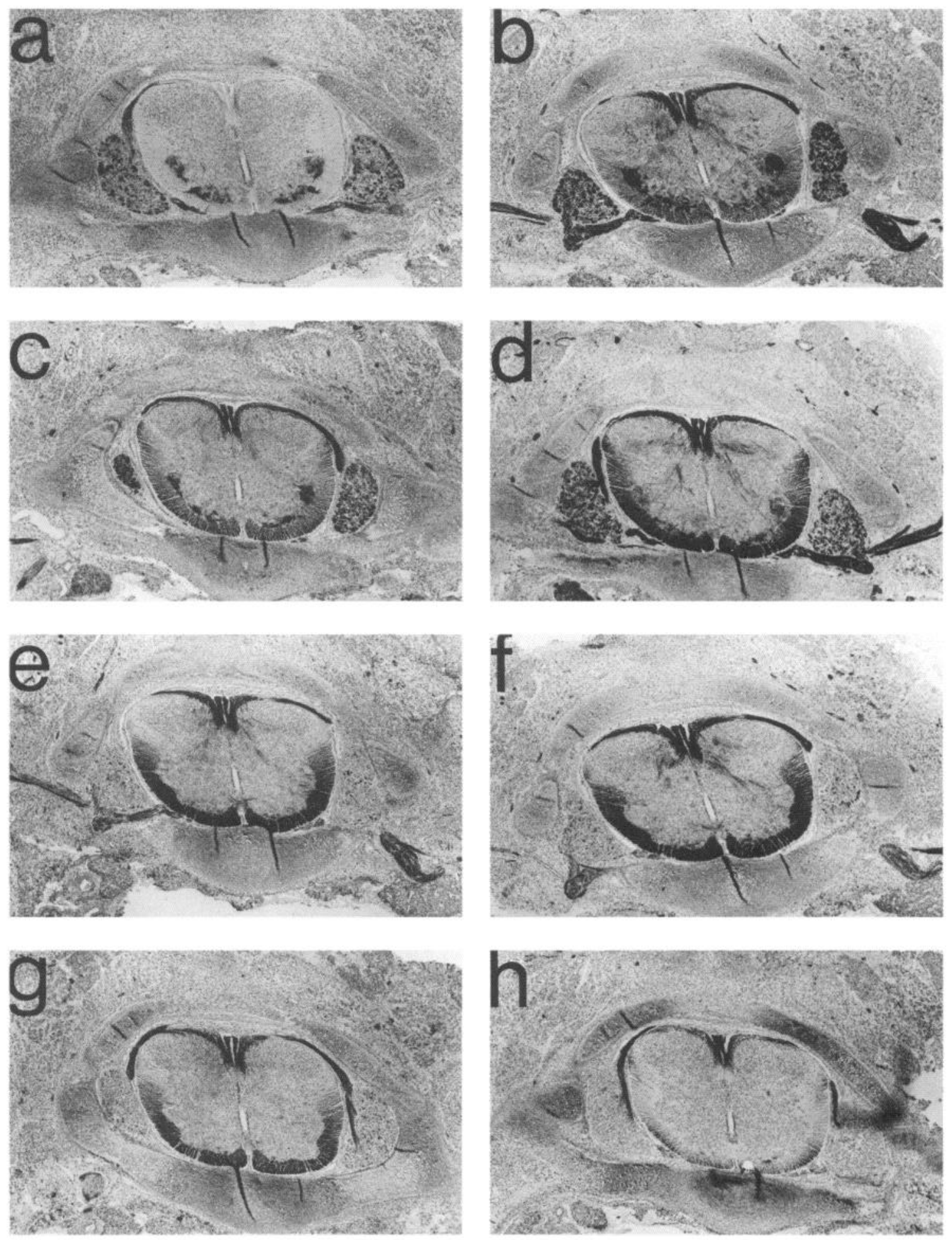

Figure 10. NF immunoreactivity in the spinal cord and DRG of E19 rat embryos. The mAbs, their dilutions, and their properties were as follows: $a$, RMdO9, diluted $\times 100$ : NF-H-specific $\mathrm{P}[-]$ type; $b$, RMdO9, undiluted; $c$, RMdO10, undiluted: NF-M-specific $\mathrm{P}[$ ind-core]; $d$, RMO93, diluted $\times$ 100: NF-M-specific $\mathrm{P}[+]$ type; $e$, Ta51, diluted $\times 10$ : NF-H-specific $\mathrm{P}[+]$ type; $f$, RMO217, undiluted: NF-H-specific $\mathrm{P}[++]$ type; $g, \mathrm{RMO} 24$, undiluted: NF-H-specific $\mathrm{P}[+++]$ type; $h$, RMO55, diluted $\times 100$ : NF-M-specific $\mathrm{P}[++]$ type. All sections are from a series of 50 that were cut at $6 \mu \mathrm{m}$, thus covering a tissue thickness of less than $400 \mu \mathrm{m}$. All sections are counterstained with hematoxylin. The width of each panel represents approximately $2700 \mu \mathrm{m}$. 
their lateral sidearms, including (1) that NFs, when isolated, appear to be separate and randomly dispersed rather than arrayed in parallel or linked by numerous cross-bridges (e.g., Schlaepfer, 1979; Carden and Eagles, 1983), (2) that isolated projecting domains of NF-H do not appear to interact in vitro, but appear, rather, as monomers (Chin et al., 1983; Eagles et al., 1985; Carden and Eagles, 1986), (3) that dendritic NFs, which contain non- or poorly phosphorylated NF-H (e.g., Sternberger and Sternberger, 1983; Shaw et al., 1986; Lee et al., 1987), are more closely spaced than axonal NFs containing heavily phosphorylated NFs (Hirokawa et al., 1984), (4) that similar close spacings are exhibited by axonal NFs during development (Hirokawa et al., 1984) at a time when their phosphorylation is incomplete, (5) that enzymatic dephosphorylation reduced the pellet size of isolated bovine NFs (M. J. Carden, unpublished observations), and (6) that a cross-linked matrix of NFs could be expected to inhibit, rather than facilitate, rapid organelle transport through axoplasm and would require energy input for the breakage of such linkages during passage of transport particles. The repulsion theory provides a simple, yet elegant, explanation for the way NFs adopt the space-filling function within axoplasm, as proposed by Hoffman and coworkers (Hoffman et al., 1984, 1985a). Also, the association between NF phosphorylation and the slowing of axonal transport during development could be explained by a phosphorylation-mediated disconnection of NFs from the transport mechanism, as opposed to being the consequence of increased drag due to the formation of crossbridges (Willard and Simon, 1983).

At present, the nature, as well as the effects, of NF phosphorylation is poorly understood. Nevertheless, an important feature of NF phosphorylation has been documented in this study, namely, the prominent imprinting of NF phosphorylation shortly after the initial expressions of NF proteins and, especially, the establishment of adult patterns of phosphorylation (i.e., proximodistal gradation) early in development. Many questions, however, remain concerning the identity of the kinase system(s) involved in NF phosphorylation, the mechanisms that regulate the activation of kinase(s) at specific sites along the neuraxis, and the nature of phosphorylation sites on NF proteins, their relative reactivities with different kinase systems, their sequence of occupancy and the relative effects of their occupancies on the biophysical and biochemical properties of NFs. The availability of a well-characterized library of speciesspecific antibody probes, which distinguishes differential states of NF phosphorylation (Lee et al., 1987) should be very helpful in providing further insights into the nature of NF phosphorylation.

\section{References}

Adelmann, H. B. (1925) The development of the neural folds and cranial ganglia of the rat. J. Comp. Neurol. 39: 19-171.

Altman, J., and S. A. Bayer (1982) Development of the Cranial Nerve Ganglia and Related Nuclei in Rat (Advances in Anatomy, Embryology and Cell Biology, vol. 74), Springer-Verlag, Berlin.

Altman, J., and S. A. Bayer (1984) The Development of the Rat Spinal Cord (Advances in Anatomy, Embryology and Cell Biology, vol. 85), Springer-Verlag, Berlin.

Altman, J., and S. A. Baycr (1986) The development of the Rat Hypothalamus (Advances in Anatomy, Embryology and Cell Biology, vol. 100), Springer-Verlag, Berlin.

Anderton, B. H., R. Thorpe, J. Cohen, S. Selvendran, and P. Woodhams (1980) Specific neuronal localization by immunofluorescence of 10 nm filament polypeptides. J. Neurocytol. 9: 835-844.

Autilio-Gambetti, L., R. Crane, and P. Gambetti (1986) Binding of Bodian's silver and monoclonal antibodies to defined regions of hu- man neurofilament subunits: Bodian's silver reacts with a highly charged unique domain of neurofilaments. J. Neurochem. 46: 366370.

Balkema, G. W., and U. C. Drager (1985) Light dependent antibody labelling of photoreceptors. Nature 316: 630-633.

Beaudoin, A. R. (1980) Embryology and teratology. In The Laboratory Rat, vol. 2, H. J. Baker, J. R. Lindsey, and S. H. Weisbroth, eds., pp. 75-101, Academic, New York.

Bennett, G. S., and C. DiLullo (1985a) Expression of neurofilament protein by the precursors of a subpopulation of ventral spinal cord neurons. Dev. Biol. 107: 94-106.

Bennett, G. S., and C. DiLullo (1985b) Slow posttranslational modification of a neurofilament protein. J. Cell Biol. 100: 1799-1804.

Bignami, A., T. Raju, and D. Dahl (1982) Localization of vimentin, the nonspecific intermediate filament protein, in embryonal glia and in early differentiating neurons. In vivo and in vitro immunofluorescence study of the rat embryo with vimentin and neurofilament antisera. Dev. Biol. 91: 286-295.

Bizzi, A., R. C. Crane, L. Autilio-Gambetti, and P. Gambetti (1984) Aluminum effect on slow axonal transport: A novel impairment of neurofilament proteins. J. Neurosci. 4: 722-731.

Black, M. M., P. Keyser, and E. Sobel (1986) Interval between the synthesis and assembly of cytoskeletal proteins in cultured neurons. J. Neurosei. 6: 1004-1012.

Boycott, B. B., E. G. Gray, and R. W. Guillery (1961) Synaptic structure and its alterations with environmental temperature: A study by light and electron microscopy of lizards. Proc. R. Soc. Lond. [Biol.] 154: 151-172.

Calvert, R., and B. H. Anderton (1982) In vivo metabolism of mammalian neurofilament polypeptides in developing and adult rat brain. FEBS Lett. 145: 171-175.

Carden, M. J., and P. A. M. Eagles (1983) Neurofilaments from ox spinal nerves. Isolation, disassembly, reassembly and cross-linking properties. Biochem. J. 215: 227-237.

Carden, M. J., and P. A. M. Eagles (1986) Chemical cross-linking analyses of ox neurofilaments. Biochem. J. 234: 587-591.

Carden, M. J., W. W. Schlaepfer, and V. M.-Y. Lee (1985) The structure, biochemical properties and immunogenicity of neurofilament peripheral regions are determined by phosphorylation state. J. Biol. Chem. 260: 9805-9817.

Chin, T.-K., P. A. M. Eagles, and A. Maggs (1983) The proteolytic digestion of ox neurofilaments with trypsin and alpha-chymotrypsin. Biochem. J. 215: 239-252.

Cochard, P., and D. Paulin (1984) Initial expression of neurofilaments and vimentin in the central and peripheral nervous system of the mouse embryo in vivo. J. Neurosci. 4: 2080-2094.

Dahl, D. (1980) Study on the immunological crossreactivity of neurofilament polypeptides in axonal preparations of bovine brain. FEBS Lett. 111: 152-156.

Dahl, D., and A. Bignami (1986) Neurofilament phosphorylation in development. A sign of axonal maturation? Exp. Cell Res. 162: 220230.

Dahl, D., C. J. Crosby, E. E. Gardner, and A. Bignami (1986) Delayed phosphorylation of the largest neurofilament protein in rat optic nerve development. J. Neurosci. Res. 15: 513-519.

Debus, E., K. Weber, and M. Osborn (1983) Monoclonal antibodies specific for glial fibrillary acidic (GFA) protein and for each of the neurofilament triplet polypeptides. Differentiation 25: 193-203.

Dennis, M. J., L. Ziskind-Conhaim, and A. J. Harris (1981) Development of neuromuscular junctions in rat embryos. Dev. Biol. 81 : 266-279.

Drager, U. C., and A. Hofbauer (1984) Antibodies to heavy neurofilament subunit detect a subpopulation of damaged ganglion cells in the retina. Nature 309: 624-626.

Eagles, P. A. M., J. M. Hopkins, R. Rao, and T.-K. Chin (1985) Neurofilament sidearms, proteolysis and phosphorylation. In Proceedings of the 43rd Annual Meeting of the Electron Microscopy Society of America, G. W. Bailey, ed., pp. 744-747, San Francisco Press, San Francisco.

Gambetti, P., L. Autilio-Gambetti, and S. C. Papasozomenos (1981) Bodian's silver method stains neurofilament polypeptides. Science 213: $1521-1522$

Geisler N., and K. Weber (1981) Self-assembly in vitro of the 68,000 molecular weight component of the mammalian neurofilament triplet proteins into intermediate-sized filaments. J. Mol. Biol. 151: 565571. 
Geisler, N., S. Fischer, J. Vanderkerckhove, J. Van Damme, U. Plessmann, and K. Weber (1985) Protein-chemical characterization of $\mathrm{NF}-\mathrm{H}$, the largest mammalian neurofilament component; intermediate filament-type sequences followed by a unique carboxy-terminal extension. EMBO J. 4: 57-63.

Glicksman, M. A., and M. Willard (1985) Differential expression of the three neurofilament polypeptides. Ann. NY Acad. Sci. 455: 479491.

Goldstein, M. E., H. S. Cooper, J. Bruce, M. J. Carden, V. M.-Y. Lee, and W. W. Schlaepfer (1987) Phosphorylation of neurofilament proteins and chromatolysis following transection of rat sciatic nerve. J. Neurosci. 7: 1586-1594.

Harry, J. G., J. F. Goodrum, and P. Morell (1985) The postnatal development of glial fibrillary acidic protein and neurofilament triplet proteins in rat brain stem. Int. J. Dev. Neurosci. 3: 349-352.

Hickey, W. F., V. M.-Y. Lee, J. Q. Trojanowski, L. J. McMillan, T. J. McKearn, J. Gonatas, and N. K. Gonatas (1983) Immunohistochemical application of monoclonal antibodies against myelin basic protein and neurofilament triplet protein subunits: Advantages over antisera and technical limitations. J. Histochem. Cytochem. 31: 11261135.

Hirokawa, N., M. A. Glicksman, and M. Willard (1984) Organization of mammalian neurofilament polypeptides within the neuronal cytoskeleton. J. Cell Biol. 98: 1523-1536.

Hotfman, P. N., and R. J. Lasek (1975) The slow component of axonal transport: Identification of major structural polypeptides of the axon and their generality among mammalian neurons. J. Cell Biol. 66: 351-366.

Hoffman, P. N., R. J. Lasek, J. W. Griffin, and D. L. Price (1983) Slowing of axonal transport of neurofilament proteins during development. J. Neurosci. 3: 1694-1700.

Hoffman, P. N., J. W. Griffin, and D. L. Price (1984) Control of axonal caliber by axonal transport. J. Cell Biol. 99: 705-714.

Hoffman, P. N., J. W. Griffin, B. G. Gold, and D. L. Price (1985a) Slowing of neurofilament transport and the radial growth of developing nerve fibers. J. Neurosci. 5: 2920-2929.

Hoffman, P. N., G. W. Thompson, J. W. Griffin, and D. L. Price (1985b) Changes in neurofilament transport coincide temporally with alterations in the caliber of axons in regenerating motor fibers. J. Cell Biol. 101: 1332-1340.

Julien, J.-P., and W. E. Mushynski (1982) Multiple phosphorylation sites in mammalian neurofilament polypeptides. J. Biol. Chem. 257: 10467-10470.

Julien, J.-P., and W. E. Mushynski (1983) The distribution of phosphorylation sites among identified proteolytic fragments of mammalian neurofilaments. J. Biol. Chem. 258: 4019-4025.

Komiya, K., T. Tashiro, and M. Kurokawa (1986a) Phosphorylation of neurofilament proteins during their axonal transport. Biomed. Res. 7: 345-348.

Komiya, K., T. Tashiro, and M. Korukawa (1986b) Occurrence of faster migrating neurofilament proteins as revealed by their phosphorylation. Biomed. Res. 7: 359-363.

Lee, V. M.-Y. (1985) Neurofilament protein abnormalities in PC12 cells: Comparison with neurofilament proteins of normal cultured rat sympathetic neurons. J. Neurosci. 5: 3039-3046.

Lee, V. M.-Y., H.-L. Wu, and W. W. Schlaepfer (1982) Monoclonal antibodies recognize individual neurofilament triplet proteins. Proc. Natl. Acad. Sci. USA 79: 6089-6092.

Lee, V. M.-Y., C. D. Page, H.-L. Wu, and W. W. Schlaepfer (1984) Monoclonal antibodies to gel excised glial filament protein and their reactivity with other intermediate filament proteins. J. Neurochem. 42: $25-32$.

Lee, V. M.-Y., M. J. Carden, and W. W. Schlaepfer (1986a) Structural similarities and differences between neurofilament proteins from five different species as revealed using monoclonal antibodies. J. Neurosci. 6: 2179-2186.

Lee, V. M.-Y., M. J. Carden, and J. Q. Trojanowski (1986b) Novel monoclonal antibodies provide evidence for the in situ existence of a non-phosphorylated form of the largest neurofilament subunit. $J$. Neurosci. 6: 850-858.

Lee, V. M.-Y., M. J. Carden, W. W. Schlaepfer, and J. Q. Trojanowski (1987) Monoclonal antibodies distinguish several differentially phosphorylated states of the two largest rat neurofilament subunits (NF-H and NF-M) and demonstrate their existence in the normal nervous system of adult rats. J. Neurosci. 7: 3474-3488.

Liem, R. K. H., and S. B. Hutchison (1982) Purification of individual components of the neurofilament triplet: Filament assembly from the 70,000 dalton subunit. Biochemistry 21: 3221-3226.

Liem, R. K. H., S.-H. Yen, G. D. Salomon, and M. L. Shelanski (1978) Intermediate filaments in nervous tissue. J. Cell Biol. 79: 637-645.

Lifsics, M. R., and R. C. Williams, Jr. (1984) Physicochemical characterization of the 68,000 -dalton protein of bovine neurofilaments. Biochemistry 23: 2866-2875.

Luca, F. C., G. S. Bloom, and R. B. Vallee (1986) A monoclonal antibody that cross-reacts with phosphorylated epitopes on two microtubule-associated proteins and two neurofilament polypeptides. Proc. Natl. Acad. Sci. USA 83: 1006-1010.

Miller, C. C. J., J.-P. Brion, R. Calvert, T.-K. Chin, P. A. M. Eagles, M. J. Downes, J. Flament-Durand, M. Haugh, J. Kahn, A. Probst, I. Ulrich, and B. H. Anderton (1986) Alzheimer's paired helical filaments share epitopes with neurofilament side arms. EMBO J. 5: 269276.

Minami, Y., S. Endo, and H. Sakai (1984) Participation of the $200 \mathrm{~K}$ or $150 \mathrm{~K}$ subunit of neurofilament in construction of the filament core with $70 \mathrm{~K}$ subunit and promotion of tubulin polymerization by incorporated 200K subunit. J. Biochem. (Tokyo) 96: 1481-1490.

Nestler, E. J., and P. Greengard (1984) Protein Phosphorylation in the Nervous System, Wiley, New York.

Nixon, R. A, and K. B. Logvinenko (1986) Multiple fates of newly synthesized neurofilament proteins: Evidence for a stationary neurofilament network distributed nonuniformly along axons of retinal ganglion cell neurons. J. Cell Biol. 102: 647-659.

Noetzel, M. J., B. I. Roots, and H. C. Agrawal (1986) Appearance and phosphorylation of the 210 kdalton neurofilament protein in newborn rat brain, spinal cord and sciatic nerve. Neurochem. Res. 11: 363374.

Nona, S. N., S. C. Trowell, and J. R. Cronley-Dillon (1985) Postnatal developmental profiles of filamentous actin and of $200 \mathrm{kDa}$ neurofilament polypeptide in the visual cortex of light- and dark-reared rats and their relationship to critical period plasticity. FEBS Lett. 186: $111-115$

Nornes, H. O., and G. D. Das (1974) Temporal pattern of neurogenesis in spinal cord of rat. I. An autoradiographic study-time and sites of origin and migration and settling patterns of neuroblasts. Brain Res. 73: $121-138$

Pachter, J. S., and R. K. H. Liem (1984) The differential appearance of neurofilament triplet polypeptides in the developing rat optic nerve. Dev. Biol. 103: 200-210.

Potter, H. D. (1971) The distribution of neurofibrils coextensive with microtubules and neurofilaments in dendrites and axons of the tectum, cerebellum and pallium of the frog. J. Comp. Neurol. 143: 385410.

Prochiantz, A., A. Dclacourtc, M.-C. Daguet, and D. Paulin (1982) Intermediate filament proteins in mouse brain cells cultured in the presence or absence of fetal calf serum. Exp. Cell Res. 139: 404-410.

Raju, T., A. Bignami, and D. Dahl (1981) In vivo and in vitro differentiation of neurons and astrocytes in the rat embyro. Immunofluorescence study with neurofilament and glial filament antisera. Dev. Biol. 85: 344-351.

Schlaepfer, W. W. (1979) Nature of mammalian neurofilaments and their breakdown by calcium. In Progress in Neuropathology. vol. 4, H. M. Zimmerman, ed., pp. 101-123, Raven, New York.

Schlaepfer, W. W., and R. G. Lynch (1977) Immunofluorescence studies of neurofilaments in the rat and human peripheral and central nervous system. J. Cell Biol. 74: 241-250.

Schlaepfer, W. W., V. M.-Y. Lee, and H.-L. Wu (1981) Assessment of immunological propertics of ncurofilament triplet proteins. Brain Res. 226: 259-272.

Schmidt, M. L., M. J. Carden, V. M.-Y. Lee, and J. Q. Trojanowski (1987) Phosphate dependent and independent neurofilament epitopes in the axonal swellings of patients with motor neuron disease and controls. Lab. Invest. 56: 282-294.

Shaw, G., and K. Weber (1982) Differential expression of neurofilament triplet proteins in brain development. Nature 298: 277-279.

Shaw, G., and K. Weber (1983) The structure and development of the rat retina: An immunofluorescence microscopical study using antibodies specific for intermediate filament proteins. Eur. J. Cell Biol. 30: $219-232$

Shaw, G., M. Osborn, and K. Weber (1981) An immunofluorescence microscopical study of the neurofilament triplet proteins, vimentin and glial fibrillary acidic protein in the adult rat brain. Eur. J. Ccll Biol. 26: 20-27. 
Shaw, G., E. Debus, and K. Weber (1984) The immunological relatedness of neurofilament proteins of higher vertebrates. Eur. J. Cell Biol. 34: 130-136.

Shaw, G., G. A. Banker, and K. Weber (1985) An immunofluorescence study of neurofilament protein expression by developing hippocampal neurons in tissue culture. Eur. J. Cell Biol. 39: 205-216.

Shaw, G., M. Osborn, and K. Weber (1986) Reactivity of a panel of neurofilament antibodies on phosphorylated and dephosphorylated neurofilaments. Eur. J. Cell Biol. 42: 1-9.

Smith, M. E., V. Perret, and L. F. Eng (1984) Metabolic studies in vitro of the CNS cytoskeletal proteins: Synthesis and degradation. Neurochem. Res. 9: 1493-1507.

Sternberger, L. A., and N. H. Sternberger (1983) Monoclonal antibodies distinguish phosphorylated and nonphosphorylated forms of neurofilaments in situ. Proc. Natl. Acad. Sci. USA 80: 6126-6130.

Toyoshima, I., M. Satake, and T. Miyatake (1984) Differences in the neurofilament proteins between the perikaryon and axon of the bovine spinal ganglion. Biomed. Res. 5: 459-464.

Toyoshima, I., A. Yamamoto, M. Satake, and T. Miyatake (1985) Perikaryal proteins that react with an antibody against the $220 \mathrm{~K}$ component of axonal neurofilaments. Biomed. Res. 6: 339-342.

Trojanowski, J. Q., M. A. Obrocka, and V. M.-Y. Lee (1983) A comparison of eight different chromogen protocols for the demonstration of immunoreactive neurofilaments or glial filaments in rat cerebellum using the peroxidase-antiperoxidase method and monoclonal antibodies. J. Histochem. Cytochem. 31: 1217-1223.

Trojanowski, J. Q., M. A. Obrocka, and V. M.-Y. Lee (1985) Distribution of bovine neurofilament subunits in neurons and neuronal processes: Immunohistochemical studies of bovine cerebellum with subunit specific monoclonal antibodies. J. Histochem. Cytochem. 33: $557-563$

Trojanowski, J. Q., N. Walkenstein, and V. M.-Y. Lee (1986) Expression of neurofilament subunits in neurons of the central and peripheral nervous system: An immunohistochemical study with monoclonal antibodies. J. Neurosci. 6: 650-660.

Troncoso, J. C, P. N. Hoffman, J. W. Griffin, K. M. Hess-Kozlow, and D. L. Price (1985) Aluminum intoxication: A disorder of neurofilament transport in motor neurons. Brain Res. 342: 172-175.
Troncoso, J. C., L. A. Sternberger, N. H. Sternberger, P. N. Hoffman, and D. L. Price (1986) Immunocytochemical studies of neurofilament antigens in the neurofibrillary pathology induced by aluminum. Brain Res. 364: 295-300.

Willard, M. B., and K. L. Hulebak (1977) The intra-axonal transport of polypeptide $\mathrm{H}$ : Evidence for a fifth (very slow) group of transported proteins in the retinal ganglion cells of the rabbit. Brain Res. 136: 289-306.

Willard, M. B., and C. Simon (1983) Modulations of neurofilament axonal transport during the development of rabbit retinal ganglion cells. Cell 35: 551-559.

Willard, M. B., C. Simon, C. Baitinger, J. Levine, and P. Skene (1980) Association of an axonally transported polypeptide $(\mathrm{H})$ with $100 \mathrm{~A}$ filaments. Use of immunoaffinity electron microscope grids. J. Cell Biol. 85: 587-596.

Windle, W. F., and R. E. Baxter (1936a) The first neurofibrillar development in albino rat embryos. J. Comp. Neurol. 63: 173-188.

Windle, W. F,. and R. E. Baxter (1936b) Development of reflex mechanisms in the spinal cord of albino rat embryos. Correlations between structure and function, and comparisons with the cat and the chick. J. Comp. Neurol. 63: 189-210.

Wong, J., S. B. Hutchison, and R. K. H. Liem (1984) An isoelectric variant of the 150,000 -dalton neurofilament polypeptide. Evidence that phosphorylation state affects its association with the filament. J. Biol. Chem. 259: 10867-10874.

Wood, J. N., and B. H. Anderton (1981) Monoclonal antibodies to mammalian neurofilaments. Biosci. Rep. 1: 263-268.

Wood, J. N., N. B. Lathangue, D. R. McLachlan, B. J. Smith, B. H. Anderton, and A. J. Dowding (1985) Chromatin proteins share antigenic determinants with neurofilaments. J. Neurochem. 44: 149154.

Yen, S.-H., and K. L. Fields (1981) Antibodies to neurofilaments, glial filament, and fibroblast intermediate proteins bind to different cell types of the nervous system. J. Cell Biol. 88: 115-126.

Zackroff, R. V., W. W. Idler, P. M. Steinert, and R. D. Goldman (1982) In vitro reconstitution of intermediate filaments from mammalian neurofilament triplet polypeptides. Proc. Natl. Acad. Sci. USA 79: 754-757. 